MARCOS SAWADA SIMÕES COSTA

\title{
A SINALIZAÇÃO PELO ÁCIDO RETINÓICO E A ORIGEM EVOLUTIVA DAS CÂMARAS CARDÍACAS
}

Tese apresentada ao

Instituto de Ciências Biomédicas da Universidade de São Paulo, para obtenção do

Título de Doutor em Ciências.

Área de Concentração: Biologia Celular e Tecidual

Orientador:

Prof. Dr. José Xavier Neto

Co-Orientadora:

Prof. Dra. Marianne Bronner-Fraser

São Paulo

2009 


\section{RESUMO}

Simões-Costa MS. A sinalização pelo ácido retinóico e a origem evolutiva das câmaras cardíacas [Dissertação]. São Paulo: Instituto de Ciências Biomédicas da Universidade de São Paulo; 2008.

Nos últimos anos, nós propusemos um modelo de duas etapas para a padronização antero-posterior do coração e consequente estabelecimento das câmaras cardíacas. Ácido retinóico (AR) produzido pela enzima RALDH2 induz o destino sino atrial nos precursores cardíacos posteriores. Subsequentemente, estes precursores adquirem a capacidade de expressar RALDH2, formando uma onda caudo-rostral desta enzima. A nossa hipótese é que esta onda surgiu nos para padronizar as células precursoras da bomba circulatória ancestral em regiões de influxo e efluxo, resultando na origem das câmaras cardíacas. Para testar se a onda cauro-rostral é ancestral nos vertebrados, nós mapeamos a expressão de RALDH2 em relação ao campo cardíaco em anfíbios, vertebrados basais e no cordado invertebrado anfioxo. Nossos dados sugerem que o modelo de duas etapas está presente em anfíbios e peixes. Clonagem do gene RALDH em lampréias indica presença de AR no campo cardíaco. Em anfioxo, a caracterização do padrão de expressão do ortólogo da RALDH2 revela ausência da onda caudo-rostral. Nossos resultados sugerem que a onda caudo-rostral de RALDH2 foi cooptada nos vertebrados para padronizar o campo cardíaco no eixo AP, o que corrobora a hipotése de que este mecanismo foi importante na origem evolutiva das câmaras cardíacas.

Palavras-chave: Ácido retinóico, RALDH2, Coração, Evolução, Câmaras cardíacas, Átrio, Ventrículo. 


\begin{abstract}
Simões-Costa MS. Retinoic acid signaling and the evolutionary origins of cardiac chambers [Ph.D. Thesis]. São Paulo: Instituto de Ciências Biomédicas da Universidade de São Paulo; 2008.

In the last years, we have proposed a 2-step model for the establishment of cardiac chamber identities. Retinoic acid (RA) produced by its synthetic enzyme RALDH2, induces an atrial fate in posterior cardiac precursors of amniote embryos. Subsequently, a RALDH2 caudorostral wave engulfs posterior precursors. Our hypothesis is that this wave evolved in vertebrates to pattern an ancestral circulatory pump into AP fields, which were later fashioned into cardiac chambers. To test whether the wave is an ancestral or derived feature of amniotes, we mapped expression patterns of RALDH2 in relation to the cardiac field in amphibians, basal vertebrates and the amphioxus. Our data suggests RA signaling patterns amphibian and piscine hearts. Cloning of RALDH in lampreys shows that RA synthesis takes place in the heart field. In the amphioxus, cloning of RALDH reveals a vertebrate-like expression pattern, although the RALDH2 wave is absent. Our results support the hypothesis that the caudorostral wave of RALDH2 was coopted to pattern the vertebrate cardiac field. This supports the hypothesis that the caudorostral wave of RALDH2 was an important player in the evolutionary origin of the cardiac chambers.
\end{abstract}

Key Words: Retinoic acid, RALDH2, Heart, Evolution, Cardiac chambers, Atrium, Ventricule. 


\section{INTRODUÇÃO E REVISÃO BIBLIOGRÁFICA}


O coração vertebrado é um órgão formado por câmaras musculares, válvulas e um sistema de condução nervosa organizados em um arranjo tridimensional complexo. A história evolutiva do coração, no entanto, remonta a precursores muito mais simples. A circulação em cordados invertebrados, como tunicados e os cefalocordados, é realizada por vasos contráteis que impulsionam o fluido circulatório através de movimentos de peristalse (Figura 1) (Randall e Davie, 1980; Simoes-Costa, et al., 2005). As câmaras cardíacas, por outro lado, bombeiam um volume muito maior de fluido sem os problemas de refluxo e perda de energia inerentes às bombas peristálticas (Xavier-Neto, et al., 2007). Neste contexto, a origem das câmaras cardíacas possibilitou avanços substantivos de eficiência circulatória após o surgimento dos vertebrados.

O problema da origem do coração vertebrado representa um desafio considerável para os evolucionistas. A grande diferença de complexidade estrutural encontrada entre o coração e as bombas peristálticas dificulta a elaboração de teorias que expliquem a transição entre estas duas estruturas (Figura 1). Uma maneira de abordar esta questão é através do estudo mecanismos moleculares envolvidos na embriogenia cardíaca. Como o coração vertebrado é caracterizado pela presença das câmaras cardíacas, sua origem está ligada ao surgimento dos processos que possibilitaram a formação destes compartimentos (Simoes-Costa, et al., 2005). Portanto, uma maior compreensão da evolução do coração só será alcançada à luz dos processos morfogenéticos envolvidos na ontogenia das câmaras cardíacas.

Nos últimos anos, foram produzidas evidências que apóiam a tese de que a sinalização pelo ácido retinóico (AR), sintetizado pela enzima retinaldeído desidrogenase 2 (RALDH2, também conhecida como ALDH1A2), é o ponto central da padronização antero-posterior (AP) do campo cardíaco em câmaras ventriculares e atriais (Moss, et al., 1998; Xavier-Neto, et al., 1999; Xavier-Neto, et al., 2000). Com base nestas evidências, foi proposto um modelo para padronização cardíaca AP em amniotos (aves e mamíferos), onde os precursores posteriores são especificados para um destino sino-atrial pelo $A R$, enquanto que os precursores anteriores assumem um destino ventricular ou de conotronco na ausência deste retinóide (Rosenthal e Xavier-Neto, 2000; Xavier-Neto, et al., 2001). Em 2003, Hochgreb e colaboradores (2003) identificaram uma onda caudo-rostral de RALDH2 
como o mecanismo embrionário responsável pela comunicação do sinal AP ao campo cardíaco e pela conseqüente partição do coração entre ventrículos e átrios.

Este modelo de padronização AP cardíaca pelo $A R$ tem se mostrado consistente frente às novas evidências. Recentemente, postulamos que ele também pode ser utilizado para esclarecer a maneira pela qual os corações dos vertebrados evoluíram a partir das bombas circulatórias peristálticas dos cordados basais (Simoes-Costa, et al., 2005). De acordo com esta visão, o surgimento das câmaras cardíacas foi o resultado da padronização dos precursores da bomba peristáltica do ancestral cordado via sinalização pelo $A R$, criando segmentos cardíacos alinhados ao eixo AP. Consequentemente, a padronização AP através da sinalização por AR pode ter sido crucial para a evolução das câmaras cardíacas, fato que culminou em um grande aumento de eficiência circulatória.

Para testar esta hipótese, neste trabalho a sinalização pelo AR durante o desenvolvimento cardíaco foi investigada em cordados pertencentes a grupos taxonômicos distintos. Foram utilizados modelos já estabelecidos na biologia do desenvolvimento (Gallus gallus, Xenopus laevis, Danio rerio), assim como animais que ocupam posições relevantes na linhagem filogenética dos cordados (Petromyzon marinus, Branchiostoma floridae). O objetivo é verificar se a relação topológica entre a fonte de produção de AR e o campo cardíaco encontrado em amniotos é mantida nos vertebrados basais. Além disso, também é analisada a sinalização pelo AR durante a formação da bomba circulatória do cordado invertebrado $B$. floridae, em buscas de pistas sobre o envolvimento do AR na gênese das bombas circulatórias dos cordados basais. Os resultados obtidos indicam que a onda caudo-rostral de RALDH2 está presente em todos os vertebrados estudados, o que sugere fortemente que o mecanismo de duas etapas não é uma particularidade dos amniotos, e sim um mecanismo ancestral na formação do coração vertebrado. Isto corrobora a hipótese de que a sinalização pelo AR foi fundamental para a origem evolutiva do coração vertebrado.

A revisão bibliográfica que introduz este trabalho está organizada em quatro partes. Inicialmente será abordada a evolução do sistema cardiovascular em cordados, assunto que foi apresentado na revisão que publicamos em 2005. Na segunda parte, será feita uma breve revisão dos aspectos morfológicos e moleculares do desenvolvimento cardíaco em vertebrados. Em seguida, serão 
apresentadas informações sobre metabolismo e a sinalização pelo AR. Finalmente, serão apresentadas as informações que implicam o AR no desenvolvimento cardíaco e o programa experimental que será utilizado para testar as hipóteses formuladas por Simões-Costa e colaboradores (2005).

(A)

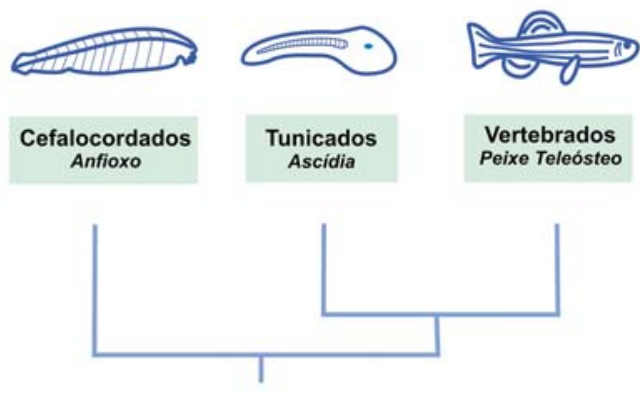

Cordados

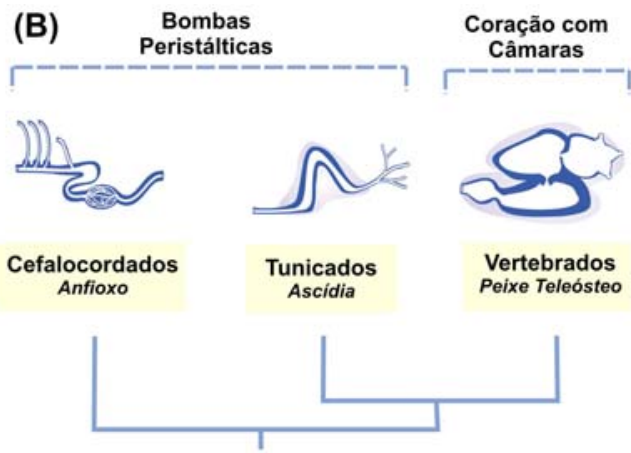

Cordados

Figura 1. Bombas circulatórias dos cordados. A) Filogenia atual do Filo Chordata. (B) O coração com câmaras, cuja eficiência é superior às bombas peristálticas dos cordados basais, é uma exclusividade dos vertebrados.

\subsection{Evolução do Sistema Cardiovascular}

O papel da criação das câmaras cardíacas na evolução dos vertebrados tem sido negligenciado. A visão dominante sobre os fatores que levaram à emergência dos vertebrados se baseia nas idéias de Gans e Northcut (1983). Estes pesquisadores sugeriram que o surgimento das células da crista neural e dos placódios foram os fatores decisivos para o sucesso dos vertebrados. Estes novos tipos celulares teriam propiciado a criação do crânio, que concentra todas as funções de aquisição e processamento de informações, e teriam resultado na geração de comportamentos adaptativos. De acordo com estes autores, a 
cefalização teria sido fundamental na evolução do comportamento predatório entre os vertebrados, e a principal razão do seu sucesso evolutivo (Gans e Northcutt, 1983; Northcutt e Gans, 1983).

Entretanto, os cenários cuidadosamente elaborados por Gans e Northcut não ofereceram nenhuma sugestão sobre o papel do sistema circulatório na emergência dos vertebrados. Isto, parece ser um equívoco, visto que, de um ponto de vista fisiológico, um sistema circulatório eficiente é fundamental para o comportamento predatório observado nos vertebrados. Esta noção é reforçada pelo fato de que câmaras cardíacas são exclusividade dos vertebrados entre os deuterostômios. Os cordados invertebrados movimentam sua circulação com o uso de vasos peristálticos, cuja eficiência é claramente inferior à do coração com câmaras (Simoes-Costa, et al., 2005).

De fato, se analisarmos as bombas circulatórias dos deuterostômios, é clara a grande diferença entre a estrutura das bombas circulatórias de hemicordados, cefalocordados e tunicados, e os corações presentes nos vertebrados (Figura 1B). Enquanto que os cordados invertebrados possuem bombas peristálticas para impulsionar a circulação, os vertebrados mais basais, como lampréias e peixesbruxa, já possuem corações com funções de influxo e efluxo (Figura 2A). Neste trabalho, a investigação da origem evolutiva do coração é iniciada mediante uma análise comparativa da anatomia das bombas circulatórias dos cordados. Esta análise permite a delineação de cenários que ajudam a esclarecer as relações evolutivas entre bombas circulatórias de cordados e o coração vertebrado.

\subsubsection{A estrutura do coração vertebrado}

O coração vertebrado é um órgão segmentado composto por quatro câmaras cardíacas: seio venoso, átrio, ventrículo e conus (ou bulbus) arteriosus (Romer, 1962; Randall, 1968; Fange, 1972; Kardong, 2002). O seio venoso e o átrio são compartimentos que recebem o sangue proveniente do sistema venoso, enquanto que o ventrículo e o conus arteriosus têm a função de propelir o sangue para o sistema arterial. Este plano básico, que é bastante evidente em vertebrados basais 
como lampréias e peixes (Fig. 2A), pode apresentar modificações consideráveis nos grupos taxonômicos mais derivados (Simoes-Costa, et al., 2005). Tais modificações, que são resultado das constantes mudanças adaptativas inerentes ao processo evolutivo, muitas vezes dificultam a identificação das câmaras cardíacas.

Conforme já mencionado, a presença das quatro câmaras cardíacas é bastante clara em lampréias e peixes teleósteos (Figura 2B). Os relatos sobre a anatomia do coração dos peixes-bruxa na literatura são conflitantes. Estes animais foram descritos como possuindo corações com apenas três câmaras cardíacas: seio venoso, átrio e ventrículo (Randall, 1968; Kardong, 2002; Pough, et al., 2002), apesar da possível presença de um conus arteriosus rudimentar (Wright, et al., 1984). Os vertebrados mais derivados, como mamíferos e aves, possuem uma redução bastante pronunciada no seio venoso e o conus arteriosus (Fig. 2B), sendo que o seio venoso é vestigial nos corações adultos e o conus arteriosus aparentemente fundiu-se parcialmente com o miocárdio ventricular. De fato, a reconstrução tridimensional de embriões de camundongo sugere que apenas átrio e ventrículo funcionam como câmaras cardíacas em mamíferos (Christoffels, et al., 2000; Moorman e Christoffels, 2003).

Outra alteração morfológica que dificulta a definição do número de câmaras cardíacas presentes em animais vertebrados são os septos atriais e ventriculares. Vertebrados basais, como peixes-bruxa, lampréias e peixes teleósteos não possuem septos em suas câmaras cardíacas. Anfíbios possuem um septo atrial enquanto que mamíferos e aves apresentam um septo atrial e um septo ventricular (Kardong, 2002). Algumas espécies de répteis, como os lagartos varanídeos, possuem dois septos ventriculares parciais e são descritos como possuindo cinco câmaras cardíacas: três ventrículos e dois átrios (Burggren e Johansen, 1982; Burggren, 1988). Portanto, ao longo do processo evolutivo, câmaras cardíacas podem regredir, sofrer fusão com outros compartimentos ou divisão em mais subcompartimentos. 
(A)

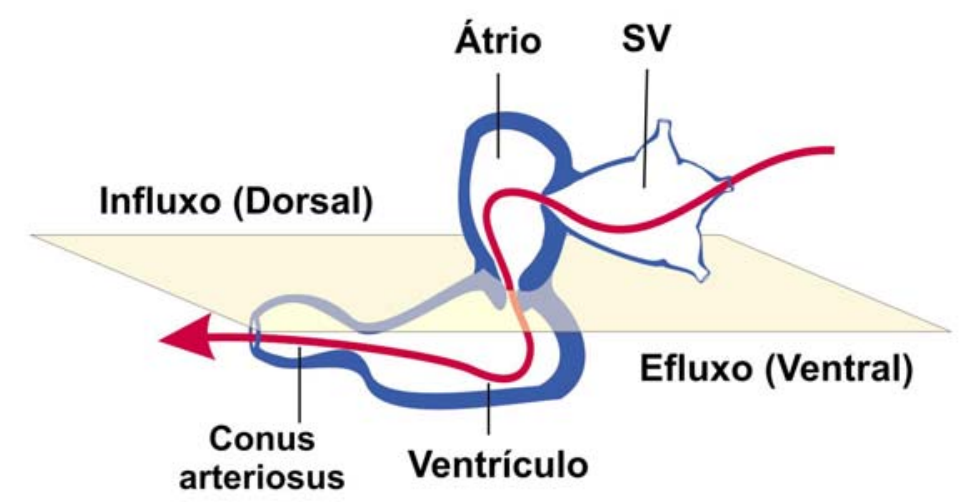

(B)

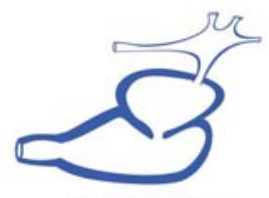

Peixe-bruxa

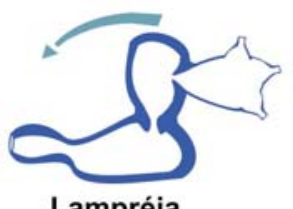

Lampréia

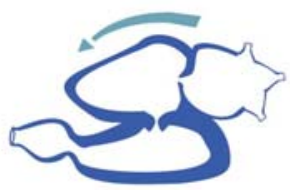

Peixe Teleósteo

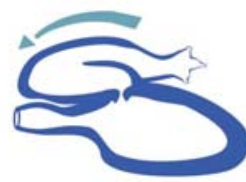

Anfibio

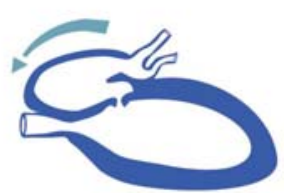

Amnioto

Figura 2. Anatomia do coração vertebrado. (A) Plano básico do coração vertebrado. $O$ átrio e o seio venoso (SV) são as câmaras de influxo, e compõe a parte dorsal do coração. O ventrículo e o conus arteriosus são as câmaras de enfluxo, estando localizadas ventralmente em relação aos compartimentos de influxo. (B) Modificações na morfologia do coração vertebrado. A organização dorso-ventral do coração sofreu alterações durante o processo evolutivo, como o deslocamento das câmaras de influxo para a região anterior (seta), septação, e a redução do seio venoso e conus arteriosos em anfíbios e peixes.

Uma dificuldade adicional no estudo da anatomia cardíaca é que as câmaras cardíacas podem ser definidas a partir de conceitos morfológicos (Fange, 1972; Bourne, 1980; Kardong, 2002) ou funcionais (Christoffels, et al., 2000). Tais conceitos foram elaborados para a análise das variações encontradas nos corações vertebrados, e são adequados para dar ênfase às adaptações presentes em grupos taxonômicos derivados. No entanto, tornam-se menos úteis quando o objetivo é, 
como no caso deste trabalho, definir um padrão para o coração vertebrado para que ele possa ser comparado com as bombas circulatórias dos cordados invertebrados. Desta forma, faz-se necessário o estabelecimento de uma definição que utilize parâmetros que sirvam a todos os vertebrados. Em 2005, Simões-Costa e colaboradores propuseram que o coração vertebrado pode ser definido como uma bomba circulatória composta por segmentos especializados em receber e propelir o sangue. Esta definição tem caráter universal entre os vertebrados pois, independente do número de câmaras cardíacas presentes, a divisão do coração em unidades de influxo e efluxo está evidenciada nos níveis anatômico, embriológico e genético.

No nível anatômico, a divisão do coração em unidades de influxo e efluxo é particularmente evidente no coração de peixes e lampréias. Nestes animais, assim como na maioria dos outros vertebrados, o seio venoso e o átrio, que por serem as câmaras de influxo recebem o sangue proveniente da circulação, estão localizadas dorsalmente em relação ao restante do órgão (Figura 2). Ao contrário, o ventrículo e o conus arteriosus estão deslocados ventralmente (Randall, 1968). Este arranjo aumenta consideravelmente a eficiência circulatória, visto que impede que o recuo causado no ventrículo por seu esvaziamento prejudique o enchimento dos átrios (Simoes-Costa, et al., 2005). Nos amniotos existe uma tendência de deslocamento das câmaras de influxo para a região anterior do coração (Figura 2B), mas mesmo assim tal organização dorso-ventral é preservada.

Diferenças entre os compartimentos cardíacos de influxo e efluxo também são evidentes no processo de desenvolvimento cardíaco. Estudos de mapa de destino mostram que os precursores de influxo e efluxo ocupam regiões diferentes do epiblasto, linha primitiva e crescente cardíaco (ver Seção 1.2.2) (DeHaan, 1963). As regiões de influxo e efluxo também possuem diferentes perfis de expressão gênica. Genes como TBX5, HRT1, RALDH2, COUPTF-I e AMHC1 são restritos aos compartimentos de influxo, enquanto que IRX-4, MLC2-V e HRT-2 são expressos nos compartimentos de efluxo (Xavier-Neto, et al., 2001; Bruneau, 2002; Moorman e Christoffels, 2003). É importante ressaltar que a expressão gênica específica para câmaras cardíacas é rara, e quando ocorre é geralmente sob forma de gradientes ao longo do eixo antero-posterior do coração (Christoffels, et al., 2000). 
Estas evidências sugerem fortemente que a segmentação do coração reflete uma programação morfogenética que divide as bombas circulatórias dos vertebrados em compartimentos com funções de influxo e efluxo. Tal organização é única entre os deuterostômios e resume o maior nível de sofisticação mecânica do sistema cardiovascular destes animais. Sob esta ótica, a grande variedade dos corações vertebrados é reduzida à um plano básico composto por segmentos de influxo e efluxo, o que facilita a comparação deste órgão com as bombas circulatórias dos cordados basais (Simoes-Costa, et al., 2005).

\subsubsection{As bombas circulatórias dos cordados invertebrados}

Em termos gerais, os sistemas circulatórios dos tunicados e cefalocordados apresentam diversas características em comum com o dos vertebrados. Todos os cordados possuem sua principal bomba propulsora acima dos vasos da faringe e dos arcos branqueais, sendo que os vasos dorsais carregam sangue para a região posterior e os vasos ventrais carregam o sangue para a região anterior (com exceção dos tunicados, que apresentam bombeamento bi-direcional) (Bourne, 1980; Kardong, 2002; Brusca e Brusca, 2003). Isto é o oposto do que ocorre com os hemicordados e com a maioria dos protostômios, que possuem fluxo sanguíneo invertido (Nubler-Jung e Arendt, 1996; Brusca e Brusca, 2003).

Os tunicados, atualmente considerados o grupo irmão dos vertebrados (Figura. 1A), possuem em comum com os últimos um sistema circulatório centralizado, com uma bomba principal sendo responsável pela propulsão do sangue (Randall e Davie, 1980; Satoh, 1994). Outra semelhança importante entre as bombas circulatórias de tunicados e vertebrados é a presença de um pericárdio rígido, uma adaptação que permite uma maior coordenação das funções de influxo e efluxo da bomba circulatória. Entretanto, a circulação dos tunicados é aberta, e seu plano vascular parece ter sofrido simplificações consideráveis ao longo da evolução (Figura 3A) (Kriebel, 1968). 
O sistema circulatório dos cefalocordados, que é o grupo cordado basal (Figura 1A), também apresenta semelhanças consideráveis com o dos vertebrados. Em particular, o plano vascular do anfioxo é quase idêntico ao dos vertebrados basais (Figura 3B) (Rahr, 1979; Randall e Davie, 1980; Rahr, 1981). É possível, portanto, relacionar os principais vasos do anfioxo com os vasos dos vertebrados. No entanto, o sistema do anfioxo não é centralizado, e os seus múltiplos vasos peristálticos não são formados por musculatura estriada. Estas duas características distanciam os cefalocordados dos vertebrados e tunicados e os aproximam dos deuterostômios basais (Rahr, 1981; Hirakow, 1985). A seguir, é apresentada uma análise mais detalhada de aspectos anatômicos e embriológicos dos sistemas circulatórios do tunicado Ciona intestinalis e do cefalocordado Branchiostoma floridae.

\subsubsection{Ciona intestinalis:}

A circulação dos tunicados é aberta e consiste de uma bomba ventral ligada a vasos sanguíneos endoteliais e seios não revestidos por endotélio. A bomba circulatória é um tubo formado por uma monocamada de mioepitélio revestido por um celoma pericárdico. Não existem câmaras, válvulas ou polaridade anteroposterior evidentes. No entanto, é possível identificar polaridade dorso-ventral nos estágios precoces do desenvolvimento, e em muitos tunicados a bomba tem forma de "V" (Figura 3A) (Davidson, B., observações não publicadas). Um fato notável sobre a bomba circulatória dos tunicados é que ela possui a habilidade de reverter a direção dos movimentos peristálticos, o que pode ser um mecanismo para compensar a ineficiência circulatória do seu sistema aberto (Kriebel, 1968; Randall e Davie, 1980).

Apesar de ser um grupo com uma posição filogenética de destaque e possuir uma bomba circulatória central, diversos aspectos do sistema circulatório dos tunicados ainda não foram elucidados. Isto se deve provavelmente ao fato de que por muito tempo a bomba circulatória dos tunicados foi considerada um órgão "pericárdico", ou seja, seria homóloga ao pericárdio e não ao coração (Randall e Davie, 1980). Adicionalmente, a capacidade desta bomba de reverter a direção da 
peristalse sugere uma diferença fundamental entre este órgão e o coração dos vertebrados.

(A)

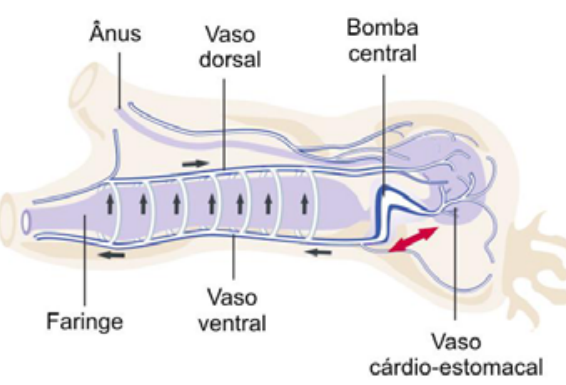

Tunicado

Ascídia

(B)
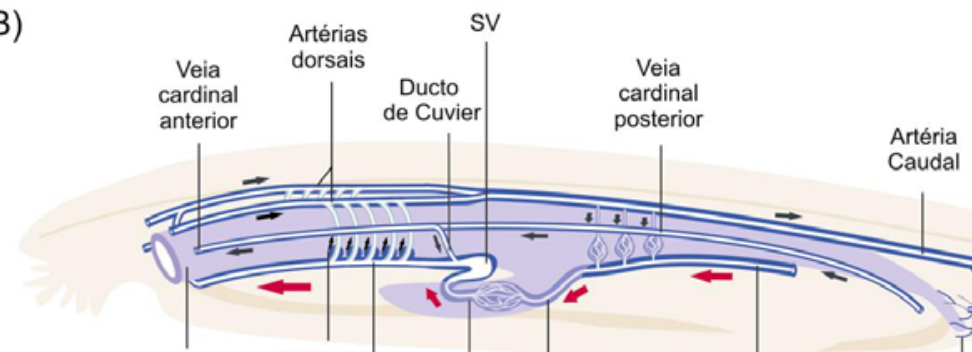

Cefalocordado

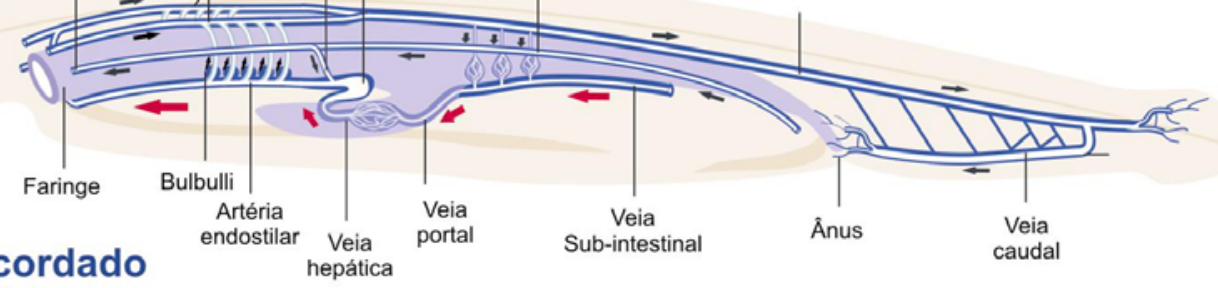

Anfioxo

Figura 3. Sistema circulatório dos cordados invertebrados. (A) Principais vasos do tunicado Ciona intestinalis, e sua bomba bi-direcional em forma de "V" invertido. (B) Plano vascular do cefalocordado Branchiostoma floridae (anfioxo). Setas vermelhas indicam a direção do fluxo criado pelas bombas circulatórias. SV: seio venoso.

Estudo recentes no tunicado $C$. intestinalis conduziram a uma revisão desta noção, mostrando que mecanismos básicos do desenvolvimento cardíaco são conservados entre amniotos e tunicados. Ortólogos de fatores de transcrição 
associados com o desenvolvimento do coração, como NKX, GATA e HAND são expressos em precursores bilaterais. Estes precursores migram ventralmente e se fundem na linha média (Davidson e Levine, 2003). Além disso, o fator de transcrição MESP parece estar implicado na especificação dos precursores cardíacos tanto em vertebrados como em C. intestinalis. No embrião de C. intestinalis, a linhagem celular que dará origem à bomba circulatória é derivada de dois blastômeros que expressam o fator de transcrição MESP, denominados B7.5 (Kitajima, et al., 2000). Durante a gastrulação, estas células sofrem divisão ao longo do eixo anteroposterior: as células mais posteriores darão origem à parte da musculatura da cauda, enquanto que as mais anteriores, denominadas células ventrais do tronco (CVTs), formam a bomba circulatória e o celoma pericárdico. No fim da neurulação, as CVTs formam grupos de precursores bilaterais que expressam NKX, GATA e HAND e que se fundem na linha média, formando uma placa de células que dará origem à bomba circulatória (Davidson e Levine, 2003).

\subsubsection{Branchiostoma floridae:}

Em uma revisão de 1997, Fishman e Chien discutem as diferenças entre os sistemas circulatórios de vertebrados e cefalocordados. Estes autores utilizam o sistema circulatório do anfioxo (B. Floridae) como referência para identificar as novidades evolutivas presentes no coração vertebrado. Estas incluem câmaras, válvulas, o endocardio, septos, o epicárdio, a circulação coronariana, um endotélio uniforme e um sistema elétrico de condução. Como nenhuma destas estruturas é observada no anfioxo, é natural presumir que os cefalocordados possuam um sistema circulatório semelhante ao cordado ancestral (Fishman e Chien, 1997).

Várias características do sistema circulatório do anfioxo podem ser consideradas rudimentares. Tais características são compartilhadas com deuterostômios basais como hemicordados e equinodermos, e até mesmo com certos protostômios (Conway Morris, 2000). A circulação do anfioxo é fechada e composta por (1) vasos ventrais e dorsais, (2) conjuntos de vasos que envolvem o 
intestino e a faringe, (3) vasos recorbertos por um endotélio descontínuo e (4) múltiplos vasos contrácteis (Figura 3B).

É difícil estabelecer um paralelo entre as bombas circulatórias do anfioxo e o coração vertebrado (Carter, 1967; Moller e Philpott, 1973; Rahr, 1979; Jefferies, 1986). O anfioxo possui quatro vasos peristálticos principais: as veias subintestinal, portal, hepática e a artéria endostilar (Figura 3B) (Moller e Philpott, 1973; Rahr, 1979). Não está claro se algum destes vasos possui homologia com o coração vertebrado. Estudos da genética e do desenvolvimento sistema circulatório do anfioxo são necessários para estabelecer se o anfioxo possui um vaso propulsor principal, e se este vaso seria o verdadeiro homólogo do coração vertebrado.

Um passo importante para resolver este dilema foi dado a partir da caracterização do padrão de expressão para o gene AmphiNk2-tin, que foi descrito como sendo o ortólogo do marcador cardíaco NKX2.5 (em mamíferos) e tinman (em drosófila) (Holland, et al., 2003). Holland e colaboradores (2003) demonstraram que o vaso subintestinal é o primeiro a expressar esse gene após a sua formação por evaginação do peritônio visceral. Como a evaginação do peritônio ocorre bilateralmente, o anfioxo também apresentaria precursores mesodérmicos bilaterais, que expressam NKX2.5 e se fundem na linha média, processo observado nos vertebrados e em drosófila (ver seção 1.2).

Holland e colaboradores (2003) sugerem que os quatro vasos peristálticos do anfioxo possuem uma origem comum na veia subintestinal. Esta seria formada a partir da fusão dos precursores bilaterias, sofreria uma expansão antero-posterior, e seria dividida em quatro vasos distintos pelo crescimento do tecido hepático. Entre estes, a artéria endostilar teria desenvolvido bulbos (agrupamentos de células musculares que propelem o sangue pelos arcos branqueais, Figura 3B) e ter se estabelecido como a bomba principal (Randall e Davie, 1980). Portanto, estas evidências sugerem que a veia subintestinal é realmente o homólogo da bomba dos tunicados e do coração vertebrado.

Outro aspecto do sistema circulatório do anfioxo que merece destaque é a natureza do seio venoso deste animal. Esta estrutura está localizada na confluência das veias principais e apesar de não estar associada a nenhuma câmara cardíaca, possui certa semelhança com o seio venoso vertebrado. No entanto, a identidade do 
seio venoso como uma câmara cardíaca é controversa, visto que ele não apresenta movimento de contração (Rahr, 1981; Farrell, 1997; Kardong, 2002), ao contrário dos seios venosos de lampréias e peixes-bruxa (Randall, 1968). Além disso, se considerarmos que a veia sub-intestinal é o verdadeiro homólogo do coração vertebrado, o seio venoso estaria no meio da bomba circulatória - o que não é consistente com a localização do seio venoso nos vertebrados. Não obstante, existem também fatos que apoiam a hipótese do seio venoso do anfioxo ser de fato homólogo ao seio venoso vertebrado, como a localização desta estrutura em relação ao vasos dos arcos branqueais (Figura 3B). Portanto, esta controvérsia somente será resolvida com estudos mais profundos da morfologia e do perfil da expressão gênica do seio venoso dos cefalocordados.

Em resumo, várias evidências recentes sugerem que os vasos peristálticos dos cefalocordados, a bomba circulatória dos tunicados e o coração dos vetebrados são parte de uma linhagem evolutiva unida por mecanismos genéticos e embriológicos comuns. Recentemente, foi feita a conjectura de que nem os cefalocordados ou os tunicados possuem, individualmente, todos os elementos necessários para que se possa inferir as características do sistema circulatório do vertebrado ancestral (Simoes-Costa, et al., 2005). C. Intestinalis, com o seu sistema circulatório centralizado e bomba composta por musculatura estriada, é provavelmente um modelo melhor para a bomba circulatória ancestral. Alternativamente, o anfioxo certamente é o modelo cordado que possui um sistema vascular mais próximo dos vertebrados. Entretanto, isto não significa que o estudo das bombas propulsoras do anfioxo ou do plano vascular de $C$. intestinalis deve ser negligenciado. Ao contrário, uma maior compreensão dos mecanismos genéticos envolvidos na formação dessas estruturas é necessária para estabelecer se elas seriam ancestrais ou o resultado de simplificações secundárias.

\subsubsection{Cenários para a evolução do coração}

$\mathrm{Na}$ literatura recente, podemos encontrar três visões distintas sobre as relações evolutivas entre bombas circulatórias de cordados e o coração vertebrado. 
Estas visões estavam ancoradas na filogenia tradicional, onde os cefalocordados, e não os tunicados, ocupavam a posição de grupo irmão dos vertebrados (Figura 4A).

Harvey (1996) sugere que os corações vertebrados se originaram a partir das bombas peristálticas dos cefalocordados, que eram então considerados o melhor modelo para o ancestral vertebrado (Figura 4B) (Harvey, 1996). Harvey (1996) entretanto não leva em consideração a bomba circulatória dos tunicados, provavelmente porque esta foi por muito tempo considerada um órgão análogo ao coração vertebrado. Por outro lado Fishman e Chien (1997) e Fishman e Olson (1997) sugerem que a bomba circulatória ancestral dos cordados era um órgão tubular e sem válvulas, similar à apresentada pelos tunicados (Fishman e Chien, 1997; Fishman e Olson, 1997). De acordo com esta visão, a artéria endostilar do anfioxo seria um intermediário entre as bombas dos tunicados e dos vertebrados (Figura 4C). No entanto, é difícil visualizar como a bomba circulatória dos tunicados, que possui pericárdio e musculatura estriada, poderia ser um precursor do vaso contrátil do anfioxo.

Em 2005, Simões-Costa e colaboradores elaboraram um cenário diferente para a evolução do coração vertebrado. Baseia-se em uma análise detalhada das bombas circulatórias dos cordados considerando fatores tais como: o tipo de musculatura que compõe as bombas, o modo de bombeamento, a presença de pericárdio, a centralização do sistema circulatório e a presença de endotélio. A partir desta análise, foi proposto um cenário mais parcimonioso, onde o cordado ancestral possuiria uma bomba central semelhante à dos tunicados. Esta bomba seria mantida nos tunicados e no ancestral dos cefalocordados e vertebrados. Os cefalocordados teriam sofrido uma descentralização do sistema circulatório, enquanto que a bomba circulatória dos vertebrados teria adquirido câmaras de influxo e efluxo. A anatomia das bombas circulatórias em cordados seria portanto explicada por uma simplificação secundária em cefalocordados e por uma elaboração do plano ancestral em vertebrados (Figura 4D).

No entanto, a base para a simplificação secundária no sistema circulatório do anfioxo foi colocada em cheque por estudos que sugeriram que os cefalocordados, e não os tunicados, estariam na base da árvore filogenética dos cordados, e que os tunicados e os vertebrados seriam grupos irmãos (Delsuc, et al., 2006). Estes estudos exigiram uma re-avaliação dos conceitos que propostos por Simões-Costa 
e colaboradores em 2005. Na realidade, a aproximação de tunicados e vertebrados resolve uma série de problemas que foram encontrados pelos autores quando estes propuseram cenários para a evolução do sistema circulatório em cordados.

(A)

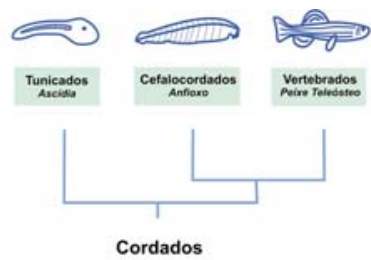

(B)

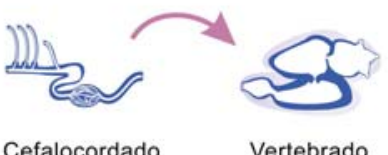

(C)

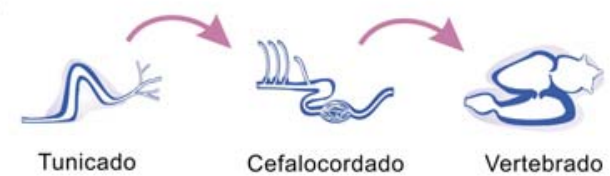

(D)

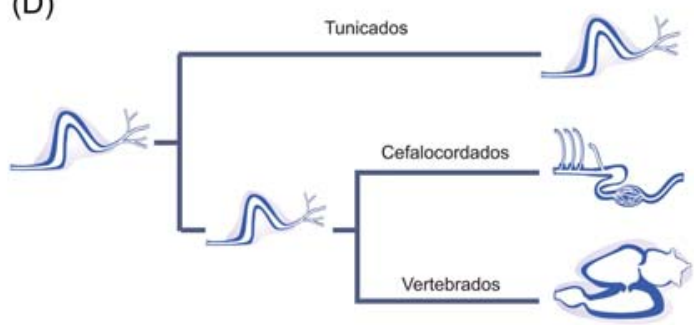

(E)

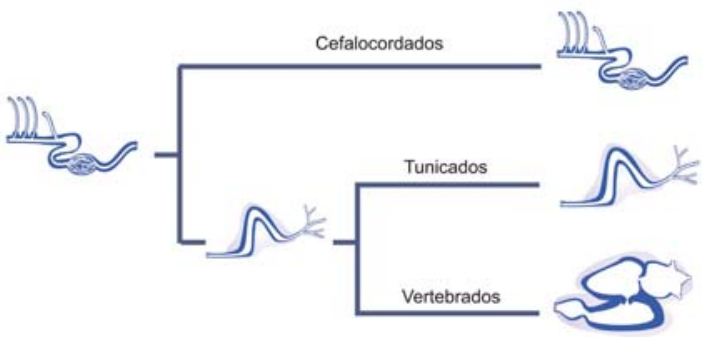

Figura 4. Cenários para a evolução do coração. (A) Filogenia tradicional, que serviu de base para as primeiras hipóteses sobre evolução cardíaca. (B) Cenário proposto por Harvey (1996), onde os vasos peristálticos do anfioxo seriam os precursores do coração com câmaras. (C) Cenário proposto por Fishman \& Chien (1997), que sugerem que os vasos peristálticos do cefalocordado seriam um intermediário entre as bombas dos tunicados e os corações vertebrados. (D) Simões-Costa e colaboradores (2005) propõem que a bomba ancestral se assemelharia à bomba dos tunicados, e que o anfioxo teria sofrido simplificação secundária. (E) Proposta de Schubert e colaboradores (2006), que leva em conta a nova filogenia: o sistema circulatório do cordado ancestral seria semelhante ao do anfioxo, enquanto que o vertebrado ancestral apresentaria uma bomba semelhante à dos tunicados.

Schubert e colaboradores (2006), ajustaram os cenários propostos por Simões Costa e colaboradores (2005) à nova filogenia. Segundo esta nova visão, o sistema descentralizado do anfioxo seria primitivo, e não simplificado secundariamente. $O$ ancestral dos tunicados e cefalocordados teriam centralizado o trabalho de 
propulsão do fluido circulatório em uma bomba principal, composta por musculatura estriada e envolvida por um pericárdio. Os tunicados teriam perdido as bombas auxiliares e adquirido a capacidade de reverter o sentido da circulação, enquanto que os vertebrados desenvolveram câmaras cardíacas, mas em muitos casos mantiveram as bombas auxiliares que estão presentes em várias espécies de peixes e anfíbios (Figura 4E) (Schubert, et al., 2006). Este cenário, que no momento parece ser o mais parcimonioso, sugere que o coração vertebrado se originou de uma bomba peristáltica semelhante à dos tunicados, que foi modificada para efetuar funções de efluxo e influxo.

\subsection{Desenvolvimento Cardíaco}

O estudo da origem evolutiva do coração vertebrado só pode ser realizado à luz dos processos morforgenéticos envolvidos no desenvolvimento cardiovascular. Tais processos são surpreendentemente conservados nos modelos vertebrados estudados. Todos os corações vertebrados são formados pela migração de precursores bilaterais que se fundem na linha média formando um tubo, que posteriormente sofre uma série de torções e é dividido por septos em diferentes compartimentos (Harvey, 2002). O grande nível de conservação observado nos vertebrados possibilitou que estudos de desenvolvimento cardíaco fossem conduzidos em modelos animais distintos, considerando-se as vantagens de cada organismo utilizado. Este tipo de abordagem comparativa permitiu que a compreensão das bases genéticas do desenvolvimento cardiovascular avançasse rapidamente.

Nesta seção, será apresentada uma breve revisão dos eventos envolvidos no desenvolvimento cardíaco, que incluem a formação do tubo cardíaco e os movimentos morfogenéticos que resultam na formação do coração com câmaras. Além disso, será feita uma breve revisão dos genes envolvidos na indução dos precursores cardíacos. No entanto, é importante ressaltar que além das fontes de células miocárdicas para o coração, outros tipos celulares de origem extracardíaca também fazem importantes contribuições e são fundamentais para a formação do 
coração (Buckingham, et al., 2005). Como exemplo, podem ser mencionadas as células da crista neural que migrarão para o polo arterial do coração, contribuindo para a septação dos grandes vasos (Stoller e Epstein, 2005), além das células derivadas do próepicárdico, as quais são fundamentais para a formação da circulação coronariana do coração (Wessels e Perez-Pomares, 2004).

\subsubsection{Formação do tubo cardíaco}

Os primeiros movimentos celulares envolvidos na formação do coração são iniciados durante a gastrulação. Neste estágio, o embrião dos amniotos é formado por duas camadas: o epiblasto, que contém os precursores de todos os tecidos que compõem o embrião, e o hipoblasto, que origina parte das membranas extraembrionárias (Stern, 2004). No início da gastrulação há a formação da fenda primitiva localizada na linha média da extremidade posterior do epiblasto. Através da fenda primitiva, células do epiblasto ingressam para o espaço entre o epiblasto e o hipoblasto, e dão origem ao endoderma e ao mesoderma (Figura 5). Na extremidade anterior da fenda primitiva se encontra o nodo de Hensen, um canal pelo qual células do epiblasto também ingressam (Stern, 2004), adquirindo rotas migratórias em direção à região anterior do embrião. As células do epiblasto que permanecem na superfície formarão o ectoderma.

Inicialmente, os precursores cardíacos estão localizados no terço posterior do disco embrionário, (Figura 5A e B). Estudos de mapa do destino determinaram que os precursores mais próximos da linha primitiva darão origem ao ventrículo e ao conus arteriosos, enquanto que os precursores mais laterais darão origem aos átrios e seio venoso. Após o ingresso através da fenda primitiva, os precursores cardíacos ocuparão o espaço entre epiblasto e hipoblasto, dando origem ao mesoderma pré-cardíaco (Garcia-Martinez e Schoenwolf, 1993; Gannon e Bader, 1995). Subsequentemente, o mesoderma pré-cardíaco migra em direção anterior e lateral para constituir o crescente cardíaco na porção anterior do embrião (Redkar, et al., 2001; Hochgreb, et al., 2003). 
Após este movimento de migração, o mesoderma cardíaco sofre transformação de mesênquima para epitélio. Esse processo, que coincide com a expressão da proteína de adesão $\mathrm{N}$-caderina, forma epitélios contendo precursores miogênicos e endocárdicos. Em seguida, os precursores do endocárdio perdem a expressão de $\mathrm{N}$-caderina e se descolam do epitélio cardíaco para formar um tubo interno dentro de uma matriz celular espessa conhecida como geléia cardíaca (Linask, et al., 1997). Os precursores cardíacos bilaterais, organizados como um tubo endocárdico interno e um manto miocárdico externo, se aproximam da linha média onde haverá a sua fusão (Navaratnam, et al., 1986; de la Cruz e Markwald, 1998).

A fusão dos precursores bilaterais do crescente forma um coração tubular composto por uma camada tubular interna de endocárdio, uma camada intermediária, a geléia cardíaca, e uma camada externa representada pelo manto miocárdico (Kaufman e Navaratnam, 1981; DeRuiter, et al., 1992). O tubo cardíaco que se forma imediatamente após a fusão é delimitado anterior e lateralmente pelo manto miocárdico e dorsalmente pelo endoderma do intestino anterior. Os precursores cardíacos se fundem no sentido AP, sendo que o processo de fusão é iniciado nos precursores do tronco, seguindo até os precursores atriais. Os precursores do seio venoso não se fundem completamente, e em amniotos este compartimento sofre fusão com ao átrio e dá origem a veia circunflexa do seio venoso (de la Cruz e Markwald, 1998; Moorman e Christoffels, 2003).

Após a sua formação, o tubo cardíaco inicia a sua atividade, ativando a circulação embrionária. O coração precoce é tradicionalmente descrito como uma bomba peristáltica, mas novos estudos que realizaram a reconstrução tridimensional do coração em movimento e rastrearam o percurso de células sanguíneas através do tubo indicam que este órgão funciona como uma bomba de hidro-impedimento. De acordo com este modelo, a força propulsora resulta da propagação de ondas elásticas pela parede do coração embrionário, sendo que a frequência das ondas é controlada de modo que haja ressonância com interferência construtiva entre as ondas de pressão geradas e refletidas. Este sistema permite a geração de um fluxo mais veloz do que o estimado para uma bomba peristáltica (Forouhar, et al., 2006). 

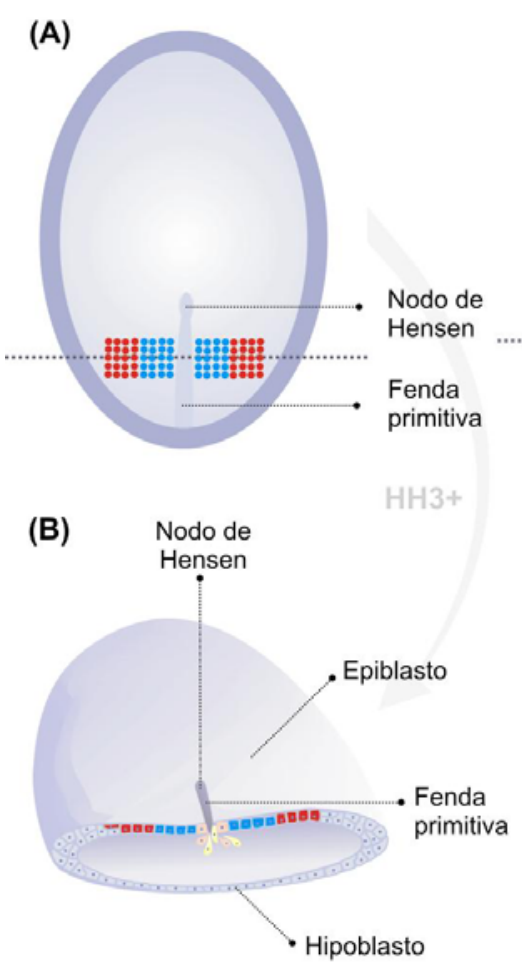

Precursores cardiacos de influxo
(C)

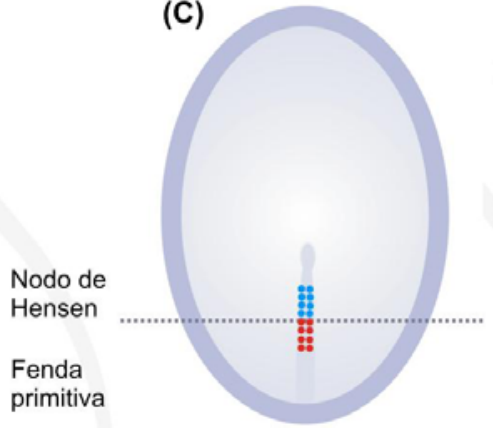

(D)

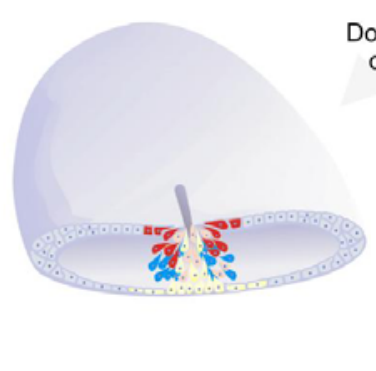

(E)

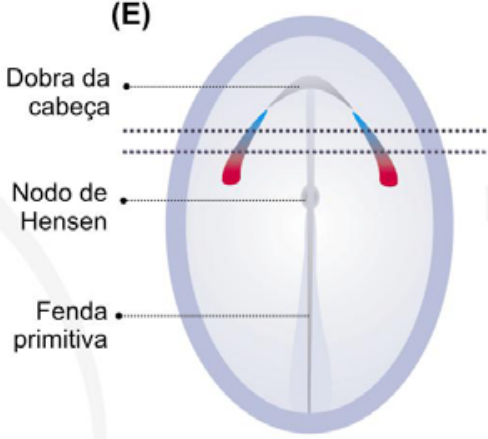

$\mathrm{HH} 4$

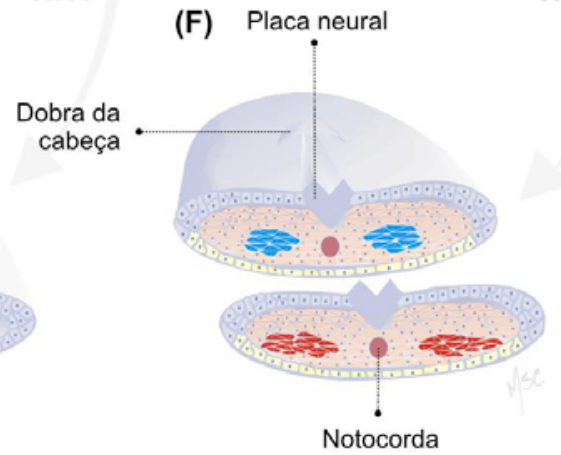

Mesoderma não cardiogênico
Precursores cardiacos de efluxo

Figura 5. Formação do crescente cardíaco em embriões de galinha. (A e B) Estudos de mapa de destino indicam que no estágio $\mathrm{HH} 3+$ os precursores cardíacos localizam-se no epiblasto, sendo que os precursores de influxo ocupam a região adjacente à linha primitiva e os precursores de efluxo estão mais distantes desta estrutura. (C e D) No estágio HH4, os precursores migram pela linha primitiva e ocupam o espaço entre o epiblasto e o hipoblasto. Os precursores de efluxo são os primeiros a ingressar. (E e F) Os precursores cardíacos migram ântero-lateralmente, dando origem a campos bilaterais no mesoderma lateral, sendo que os precursores de influxo estão localizados na região posterior do campo cardíaco, enquanto que os precursores de efluxo localizam-se na região anterior.

\subsubsection{Eventos morfogenéticos na formação do coração dos amniotos}

Após a fusão dos precursores bilaterais, o coração tubular dos amniotos sofrerá uma série de movimentos morfogenéticos que iniciarão a conversão do coração de um tubo peristáltico em um órgão multi-cameral e terão uma influência 
profunda sobre a sua morfologia e funcionamento (Figura 6). O primeiro evento é a curvatura do tubo cardíaco para o lado direito (Figura 6A). O segundo evento, a convergência, é a migração anterior do átrio comum e dos seios venosos sobre os ventrículos (Figura 6B). O terceiro evento, o encaixamento em cunha, é o posicionamento dos coxins do tronco cardíaco exatamente entre os primórdios das valvas tricúspide e mitral (Figura 6C e D).

Os três movimentos são necessários devido ao posicionamento posterior dos segmentos sinoatriais em relação aos ventrículos e conotronco. Esse arranjo contrasta com a posição das câmaras cardíacas no coração adulto quando os átrios assumem sua posição definitiva acima dos ventrículos. De fato, a disposição anatômica adulta é conseqüência da migração dos segmentos sinoatriais, primeiro em direção dorsal, para trás dos ventrículos, e em seguida, anterior, sobre os ventrículos (Figura 3B e C). Esse processo, conhecido como convergência (Kirby e Waldo, 1995), está relacionado ao dobramento céfalo-caudal observado nessa fase embrionária e, apesar de pouco estudado, é um dos mais importantes movimentos da embriogenia cardíaca tardia, pois alinha no mesmo plano crânio-caudal os coxins atrioventriculares e do conotronco, garantindo assim as bases para o processo de septação cardíaca (Manner, 2000). O encaixamento em cunha se segue ao processo de convergência e pode ser entendido como um ajuste da posição do conotronco em relação aos coxins $A V s$ e aos primórdios das valvulas tricúspide e mitral (Figura 6C e D). O movimento consiste no deslocamento do conotronco para a esquerda e dos átrios para a direita, posicionando os coxins do conotronco exatamente entre os primórdios da mitral e da tricúspide (Kirby e Waldo, 1995).

Os movimentos morfogênicos de dobramento, convergência e encaixamento em cunha para são essenciais para a correta formação do coração. O dobramento do coração para a direita, junto com o movimento dos átrios em direção anterior (convergência), alinha os segmentos de entrada e saída do coração no mesmo plano crânio-caudal. Ao mesmo tempo, o tronco arterial se move para a esquerda, colocando os coxins do conotronco em contato com os coxins AV (encaixamento em cunha). Estes processos são responsáveis pela transformação do coração tubular em um órgão multi-cameral onde a direção do fluxo é controlada por válvulas. 


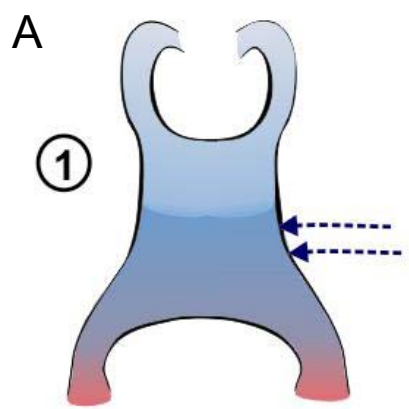

1. Dobramento do coração para direita

C

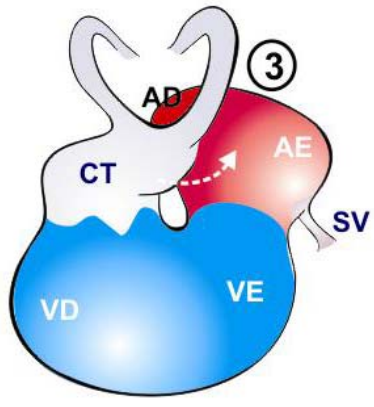

3. Encaixamento em cunha

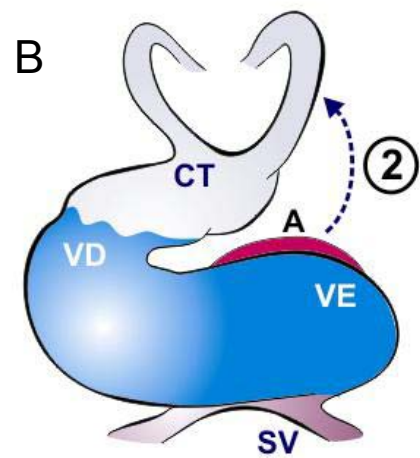

2. Convergência de influxo sobre efluxo

D

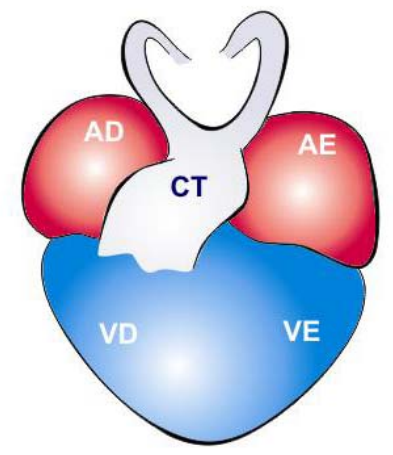

Figura 6. Movimentos morfogenéticos no desenvolvimento cardíaco de amniotos. A conversão do tubo cardíaco em coração com câmaras inicia-se com o dobramento do coração para a direita, quando o ventrículo direito e o conotronco curvam-se para este lado (1). Em seguida, o segmento do tubo cardíaco formado pelos precursores atriais movimenta-se anteriormente em direção do trato de saída, realizando um movimento de convergência da região de influxo sobre a região de efluxo (2). A configuração adulta do coração será atingida após o movimento de encaixamento em cunha, quando o conotronco move-se dorsalmente se encaixando entre os átrios direito e esquedo (3). CT: conotronco, VD: ventrículo direito, A: átrio, VE: ventrículo esquerdo, SV: seio venoso. 


\subsubsection{Desenvolvimento cardíaco em peixes e anfíbios}

Anatomicamente, os corações de $D$. rerio e $X$. laevis possuem diferenças significativas se comparados com coração adulto humano, que refletem as adaptações aos seus modos de vida (Bourne, 1980; Kardong, 2002). O coração do D. rerio é uma estrutura em forma de "S", com uma câmara atrial e uma câmara ventricular sem septação. Um sistema condutor rudimentar e válvulas cardíacas, entre o átrio e o ventrículo também estão presentes (Figura 2B) (Randall, 1968). O coração adulto de $X$. laevis possui um grau de complexidade maior (Figura 2B), sendo que há um septo que divide o átrio em dois: câmaras de influxo na região anterior do coração, e um ventrículo espesso e altamente trabeculado (Bourne, 1980).

Apesar das diferenças na anatomia do órgão adulto, os eventos precoces do desenvolvimento cardiovascular de peixes e anfíbios são surpreendentemente semelhantes aos observados em aves e mamíferos. A tabela 1 correlaciona os principais eventos no desenvolvimento cardíaco destas duas espécies, com os estágios do desenvolvimento em que tais eventos ocorrem. Em X. laevis, a mesoderme pré-cardíaca é especificada no início da gastrulação, e migra anterior e ventralmente até se alojar sob a dobra da cabeça. Um grupo de células desta região passa a expressar NKX2.5 no estágio NF 12 (Cleaver, et al., 1996). Eventualmente, um tubo linear é formado, sendo composto por uma camada interna de endocárdio e uma camada externa de miocárdio. Este tubo sofre movimentos morfogenéticos virtualmente idênticos aos observados nos amniotos, e o resultado é um coração com átrios localizados na região anterior (Mohun, et al., 2000; Warkman e Krieg, 2007). Portanto, os princípios básicos da morfogenia cardíaca observados em galinhas e camundongos são mantidos em $X$. laevis.

Em peixes, a formação do tubo cardíaco apresenta algumas diferenças em relação aos demais modelos estudados. Em D. rerio, estudos de mapa de destino revelaram que os precursores cardíacos encontram-se adjacentes à zona marginal do embrião, dividos em dois campos bilateriais. No início da gastrulação, estes precursores ingressam pela zona marginal e migram em direção à linha média do embrião. Como nos amniotos, estes precursores serão segregados em precursores 
miocárdicos e endocárdicos, e sofrerão transição de mesênquima para epitélio. Porém, no momento da fusão dos precursores cardíacos, tanto os precursores anteriores como os posteriores convergem na linha média. Este processo resulta na formação de um cone, onde os precursores endocárdicos se encontram na região central, os precursores atriais na região mais externa, e os precursores ventriculares entre as duas camadas citadas anteriormente. Após a formação do cone, este se alonga para formar um tubo. A extremidade ventricular do tubo se forma primeiro, seguida pela extremidade atrial. Subsequentemente, há a expansão das duas câmaras cardíacas, iniciando os movimentos morfogenéticos que fazem com que os átrios se posicionem dorsalmente em relação aos ventrículos. Após dois dias de desenvolvimento, as válvulas são formadas, e o coração passa a funcionar como um órgão multicameral (Stainier, et al., 1993; Lee, et al., 1994; Stainier, 2001).

\subsubsection{Marcadores cardíacos}

No momento da especificação dos precursores cardíacos, estes se encontram sob a forma de um mesênquima confinado entre a endoderme e a ectoderme. Sinais provenientes destes dois folhetos e da mesoderme axial são responsáveis por delimitar o campo cardíaco. Atualmente, sabe-se que o campo cardíaco é definido por três condições no embrião precoce: alta concentração de BMPs (bone morphogenetic proteins), baixa concentração de proteínas da família Wingless (Wnts) e alta concentração de FGFs (fibroblast growth factors), particularmente FGF8 (Schultheiss, et al., 1997; Tzahor e Lassar, 2001; Alsan e Schultheiss, 2002). A combinação destas condições eventualmente resultará na expressão de marcadores cardíacos como NKX2.5, TBX5 e GATA4, fatores de transcrição responsáveis por ativar o programa cardíaco.

Os marcadores cardíacos são ferramentas essenciais para o estudo da embriogenia cardíaca, uma vez que possibilitam a identificação dos precursores do coração, permitindo que estes sejam diferenciados das células vizinhas. Os marcadores cardíacos clássicos incluem o NKX2.5; o fator de transcrição do tipo "zinc finger" GATA 4; o fator de transcrição do tipo "T-box", TBX5; e o membro da 
família de fatores de transcrição MADS-box, MEF2C (basic helix-loop-helix) (Brand, 2003). A expressão da maioria destes fatores é iniciada logo antes dos precursores ocuparem as suas posições no campo cardíaco.

Tabela 1. Principais eventos no desenvolvimento cardíaco de peixes e anfíbios.

\begin{tabular}{|c|c|c|c|c|}
\hline & \multicolumn{2}{|r|}{ Danio rerio } & \multicolumn{2}{|c|}{ Xenopus laevis } \\
\hline Eventos & $\begin{array}{l}\text { Horas } \\
\text { após } \\
\text { fertili- } \\
\text { zação }\end{array}$ & $\begin{array}{c}\text { Estágio de } \\
\text { desenvolvimento }\end{array}$ & $\begin{array}{l}\text { Horas } \\
\text { após } \\
\text { fertili- } \\
\text { zação }\end{array}$ & $\begin{array}{c}\text { Estágio de } \\
\text { desenvolvimento }\end{array}$ \\
\hline $\begin{array}{c}\text { Especificação do } \\
\text { campo cardíaco } \\
\text { (expressão de } \\
\text { NKX2.5) }\end{array}$ & 12 & $\begin{array}{c}\text { Gastrulação, estágio de } \\
\text { "Shield" }\end{array}$ & $15-17 \mathrm{~h}$ & $\begin{array}{c}\text { Gastrulação, } \\
\text { NF 12-14 }\end{array}$ \\
\hline $\begin{array}{c}\text { Migração para a } \\
\text { linha média }\end{array}$ & 13-18 & $\begin{array}{c}\text { Segmentação, } 5 \text { - } 15 \\
\text { somitos }\end{array}$ & $30-32$ & $\begin{array}{c}\text { Organogênese, NF } \\
26-28 \\
\end{array}$ \\
\hline $\begin{array}{c}\text { Formação do tubo } \\
\text { cardíaco }\end{array}$ & $21-22$ & Segmentação, 26 somitos & $32-35$ & $\begin{array}{c}\text { Organogênese, } \\
\text { estágios NF 31-33 }\end{array}$ \\
\hline $\begin{array}{l}\text { Início dos } \\
\text { batimentos } \\
\text { cardíacos }\end{array}$ & 22 & Organogêse, 26 somitos & 50 & $\begin{array}{l}\text { Organogênese, } \\
\text { estágios NF } 35\end{array}$ \\
\hline $\begin{array}{l}\text { Expressão gênica } \\
\text { diferencial de em } \\
\text { influxo / efluxo }\end{array}$ & 22 & Organogêse, 26 somitos & 58 & $\begin{array}{l}\text { Organogênese, } \\
\text { estágios NF } 38\end{array}$ \\
\hline $\begin{array}{l}\text { Diferenciação } \\
\text { morfológica de } \\
\text { influxo / efluxo }\end{array}$ & 30 & Prim-16 & 60 & $\begin{array}{c}\text { Organogênese, } \\
\text { estágios NF 39-40 }\end{array}$ \\
\hline $\begin{array}{c}\text { Convergência de } \\
\text { influxo sobre } \\
\text { efluxo }\end{array}$ & $30-36$ & Prim-16 a Prim-22 & $44-50$ & $\begin{array}{c}\text { Organogênese, } \\
\text { estágios NF 33-36 }\end{array}$ \\
\hline $\begin{array}{l}\text { Formação da } \\
\text { válvula } \\
\text { atrioventricular }\end{array}$ & 48 & Eclosão & $70-90$ & $\begin{array}{c}\text { Organogênese, } \\
\text { NF } 44\end{array}$ \\
\hline Septação atrial & $x$ & $x$ & 92 & NF $44-45$ \\
\hline $\begin{array}{l}\text { Coração atinge } \\
\text { morfologia } \\
\text { observada no } \\
\text { adulto }\end{array}$ & 120 & $5^{\circ}$ Dia após fertilização & 106 & NF 46 \\
\hline
\end{tabular}

Fonte: (Kimmel, et al., 1995; Mohun, et al., 2000; Stainier, 2001; Yelon, 2001; Warkman e Krieg, 2007) 
O gene homeobox NKX2.5 é um dos primeiros fatores de trancrição cardíacoespecíficos, sendo que em galinhas ele começa a ser expresso no estágio HH5 (Schultheiss, et al., 1995). A importância deste gene na formação do coração foi primeiramente identificada em drosófilas. O gene tinman, ortólogo de NKX2.5 em Drosophila melanogaster, é indispensável para a formação da bomba circulatória nestes organismos (Bodmer, 1993). Em vertebrados, há redundância funcional entre NKX2.5 e outros genes da sub família NKX2, de modo que o camundongo knockout para este gene não abole completamente a formação do tubo cardíaco. No entanto, o coração destes camundongos não realiza convergência de efluxo sobre influxo e apresenta hipotrofia do miocárdio, de modo que o resultado é a morte dos embriões em 9 dpc (dias pós coito) (Tanaka, et al., 1999). A expressão de NKX2.5 não é restrita apenas ao campo cardíaco, estando presente no endoderma e ectoderma adjacentes aos precursores cardíacos e também no endoderma e mesoderma faringeano (Schultheiss, et al., 1995). Além disso, estudos de mapa de destino mostram que uma parte dos precursores cardíacos, localizados na região posterior do campo cardíaco, não expressam este fator de transcrição (Redkar, et al., 2001).

O fator de transcrição GATA4, por sua vez, parece incluir estes precursores, tendo um domínio de expressão mais amplo que NKX2.5 . GATA4 não é expresso apenas nos precursores cardíacos, mas também no endoderma associado ao crescente cardíaco. Temporalmente, GATA4 começa a ser expresso no estágio HH5 em galinhas e em 7.0 dpc em camundongos (Jiang, et al., 1999; Kostetskii, et al., 1999). A sua inativação é letal em embriões de camundongo, visto que a fusão cardíaca é dependente de GATA4. Os embriões knockout apresentam o fenótipo de cárdia bífida e morrem entre 8.5 e $10.5 \mathrm{dpc}$ (Kuo, et al., 1997). Além disso, estudos implicam GATA4 em outros processos durante o desenvolvimento do coração, como a formação das válvulas e câmaras cardíacas e os movimentos morfogenéticos (Watt, et al., 2004).

A expressão de TBX5, um fator de transcrição da família T-box, inicialmente possui um padrão bastante semelhante ao observado em NKX2.5 e GATA4. TBX5 começa a ser expresso também no estágio $\mathrm{HH} 5$ em todo o crescente cardíaco (Yamada, et al., 2000). Após a fusão dos precursores cardíacos, a expressão de TBX5 começa a se restringir aos precursores de influxo. Durante a convergência de influxo sobre efluxo, a expressão de TBX5 avança sobre os precursores do 
ventrículo esquerdo, delimitando a fronteira entre os ventrículos esquerdo e direito, local onde haverá a formação do septo interventricular (Plageman e Yutzey, 2004; Plageman e Yutzey, 2005). Outros fatores da família T-box também estão implicados no desenvolvimento cardíaco. TBX20 também é expresso no campo cardíaco, embora o seu transcrito seja detectado mais tardiamente (HH6). Eventualmente, no estágio HH12, TBX20 passa a ser expresso em toda a extensão do tubo cardíaco, sendo que, após o início do dobramento do tubo, a expressão torna-se restrita ao ventrículo direito e trato de saída do coração (Plageman e Yutzey, 2004; Yamagishi, et al., 2004).

A família de fatores de transcrição MEF2 (myocyte enhancer factor 2) possui grande importância na diferenciação cardíaca que é conservada em protostômios e deuterostômios. Existem quatro genes MEF2 nos vertebrados (MEF2A, MEF2B, MEF2C e MEF2D) e um gene em drosófila (mef2) (Black e Olson, 1998). Em camundongos, a expressão de MEF2C inicia-se em $7.5 \mathrm{dpc}$ o que faz deste fator de transcrição um dos marcadores cardíacos mais precoces, ao lado de NKX2.5 e GATA4 (Dodou, et al., 2004). No entanto, enquanto que estes fatores possuem grande importância na especificação dos precursores cardíacos, MEF2C está envolvido na diferenciação dos cardiomiócitos. Tal conclusão foi resultado de estudos de inativação em drosófila e camundongo. Camundongos deficientes para MEF2C morrem em $9.5 \mathrm{dpc}$ devido a defeitos cardiovasculares, e drosófilas com inativação de mef2 não apresentam cardiomiócitos diferenciados (Lin, et al., 1997). Estas evidências sugerem que MEF2C é o fator de transcrição responsável por ativar as baterias de genes estruturais que precisam ser expressos para que os precursores cardíacos se diferenciem em cardiomiócitos.

A especificação dos precursores cardíacos, e a sua eventual diferenciação em cardiomiócitos ocorre através da interação entre os fatores de transcrição cardíacos. Algumas dessas interações estão representadas na Figura 8. NKX2.5, que é o fator de transcrição cardíaco ativado mais precocemente, regula positivamente MEF2C direta e indiretamente, via GATA6 e GATA4, além de regular a sua própria expressão através de feedback positivo. GATA4, por sua vez, é ativado tanto por GATA6 como pelos TBXs 4, 5 e 6, e induz expressão de MEF2C e NKX2.5. Finalmente, MEF2C ativa a transcrição de uma série de proteínas estruturais que conferem aos cardiomiócitos o seu fenótipo característico (Figura 7) 
(Davidson, 2006). Portanto, a identidade das células cardíacas é determinada por um circuito genético onde fatores de transcrição de famílias diferentes interagem regulando a transcrição uns dos outros. Esta interação resultará na ativação de uma bateria genética de proteínas estruturais que conferem às células cardíacas sua forma e função.

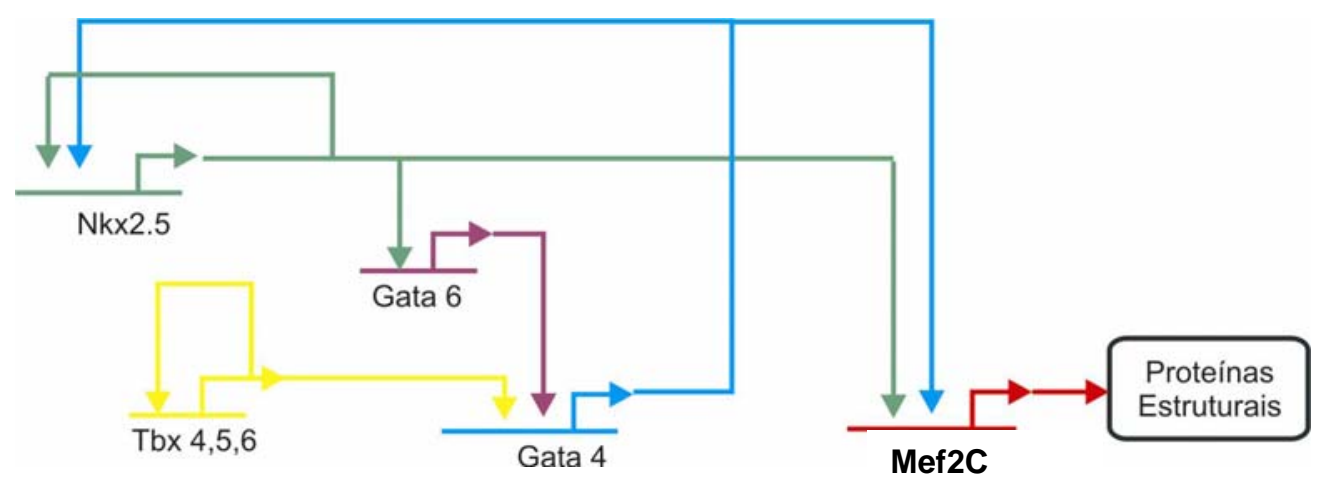

Figura 7. Interações entre os principais fatores de transcrição envolvidos no desenvolvimento cardíaco. NKX2.5, o primeiro marcador cardíaco detectado nos precursores do coração, regula a transcrição de GATA6 e MEF2C. GATA6, por sua vez, juntamente com TBX 4, 5 e 5, ativam a expressão de GATA4. NKX2.5 e GATA4 ativam a expressão de MEF2C, o fator de transcrição responsável pela ativação da transcrição dos genes estruturais característicos das células cardíacas (Adaptado de Davidson, 2006).

\subsection{Metabolismo e Sinalização pelo Ácido Retinóico}

O AR é um morfógeno de grande importância no desenvolvimento embrionário dos cordados, estando envolvido em diversos processos morfogenéticos. O AR é uma molécula lipossolúvel, e portanto possui a capacidade de difundir através das membranas de células e tecidos e agir de forma tanto autócrina como parácrina. Nos animais, a síntese do AR ocorre a partir de outros retinóides, como a vitamina $\mathrm{A}$ e o caroteno, que são adquiridos através da dieta. $\mathrm{O}$ AR possui a capacidade de se ligar a dois receptores nucleares - o receptor de 
ácido retinóico (RAR) e o receptor do retinóide $X(R X R)$ - sendo que estes regulam diretamente a expressão de diversos genes (ver Figura 9).

O papel da sinalização pelo AR no desenvolvimento começou a ser investigado por Tickle e colaboradores (1982). Segundo proposta destes autores, o AR estaria envolvido na padronização próximo-distal dos membros em G. gallus (Tickle, et al., 1982). No entanto, foi apenas após a identificação e clonagem do RAR e RXR e da elucidação dos mecanismos de síntese e de degradação do AR que este passou a ser aceito como um dos principais morfógenos atuantes na embriogênese dos vertebrados (Wang, et al., 1996; Zhao, et al., 1996; Niederreither, et al., 1999; Abu-Abed, et al., 2001; Sakai, et al., 2001).

Atualmente, sabe-se que o AR está implicado no controle de diversos processos do desenvolvimento embrionário, como morfogênese craniofacial, diferenciação neuronal e desenvolvimento do sistema visual, membros, pulmões, rins e coração. A padronização AP do eixo corporal do embrião cordado também é controlada diretamente por $A R$, que regula a expressão de genes Homeobox (Holland e Holland, 1996; Schubert, et al., 2005; Sirbu, et al., 2005). O AR também possui funções de grande importância no metabolismo do adulto, regulando processos como a visão, memória e aprendizado, resposta imune e reprodução (Novak, et al., 2008; Pino-Lagos, et al., 2008). Portanto, aspectos do metabolismo do AR têm implicações importantes em uma miríade de processos biológicos.

\subsubsection{Vias de síntese do ácido retinóico}

O AR é um di-terpenóide pequeno, de aproximadamente 300 Daltons. Terpenóides (ou isoprenóides) são compostos formados por isoprenos de cinco carbonos. No caso do AR, dois isoprenos formam uma cauda apolar que é ligada a um anel aromático. Existem três isômeros do AR: 9-cis-AR, 13-cis-AR, and all-transAR (Figura 8). A interconversão do AR parece ser mediada por enzimas microssomais e é importante na via de degradação deste retinóide. Tanto o alltrans-AR como o 9-cis-AR podem atuar na regulação gênica durante o desenvolvimento embrionário (Marchetti, et al., 1997). 


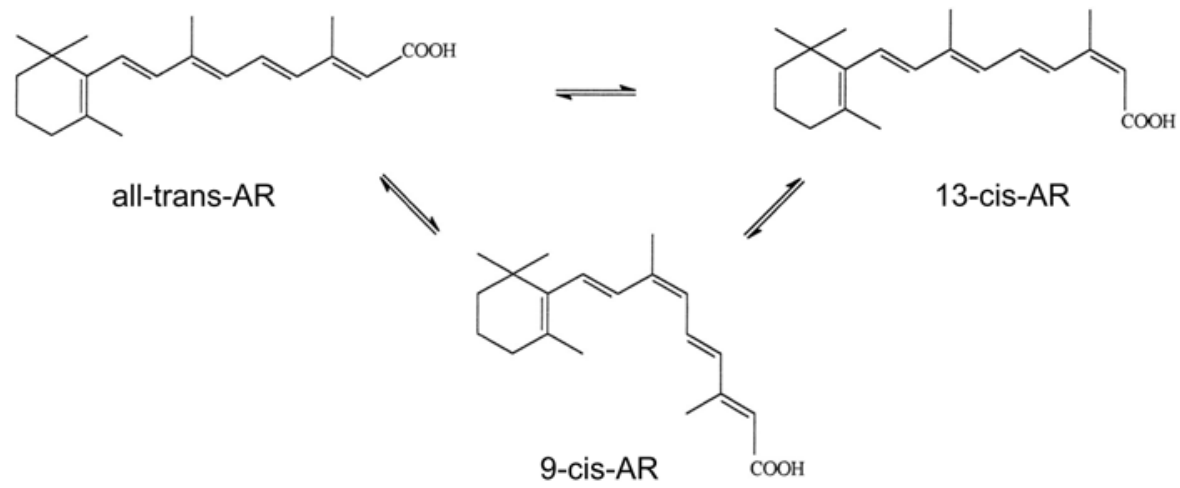

Figura 8. Os três estereoisômeros do ácido retinóico (AR). (adaptado de (Marchetti, et al., 1997).

O AR não pode ser sintetizado de novo por animais. Sua produção ocorre a partir de precursores como o retinol. O retinol (ou Vitamina A) é adquirido em alimentos de origem animal sob forma de um éster - geralmente o retinil palmitato e convertido em um álcool carboxilíco no intestino delgado. Um outro precursor do AR de grande importância é o caroteno $\left(\mathrm{C}_{40} \mathrm{H}_{56}\right)$, um polímero de oito isoprenos sintetizados por bactérias, protistas, fungos e plantas, também obtido pelos animais através da dieta (Lubzens, et al., 2003; Irie, et al., 2004; Harrison, 2005).

A síntese do AR requer duas reações de oxidação. A primeira delas é importante para a formação do retinaldeído, um composto altamente instável e de alta toxicidade, mas indispensável para a obtenção de AR. Quando o precursor utilizado é o retinol, este é oxidado a retinaldeído pela ação das álcool desidrogenases (ADHs) ou desidrogenases microsomais de cadeia curta (SDRs), em uma reação dependente de NAD. Alternativamente, quando o precursor é o caroteno, este sofre uma clivagem oxidativa simétrica catalizada pela enzima $\beta-\beta$ caroteno-15,15'-oxigenase (BCO-I), que resulta em duas moléculas de retinaldeído (Figura 9) (Duester, 2000; von Lintig e Vogt, 2004; Simoes-Costa, et al., 2008). No entanto, a expressão do ortólogo BCO-II inicia-se tardiamente durante o desenvolvimento de vertebrados, o que sugere que a oxidação de retinol pelas ADHs é a fonte primordial de retinaldeído durante a embriogenia (von Lintig e Vogt, 2004). 
De fato, as ADHs possuem ampla distribuição tecidual nos estágios precoces do desenvolvimento, sendo que uma delas, a $\mathrm{ADH} 3$, é ubíqua (Molotkov, et al., 2002). Isto sugere que praticamente todas as células embrionárias têm a capacidade de produzir retinaldeído. Portanto, a regulação dos tipos celulares onde o AR estará disponível não parece estar sob o controle das ADHs ou SDRs. Este controle é aparentemente exercido durante a segunda reação de oxidação, que é realizada pelas retinaldeído desidrogenases (RALDHs). As RALDHs oxidam o retinaldeído a $A R$ em uma reação irreversível dependente de NAD (Wang, et al., 1996; Zhao, et al., 1996) (Figura 9).

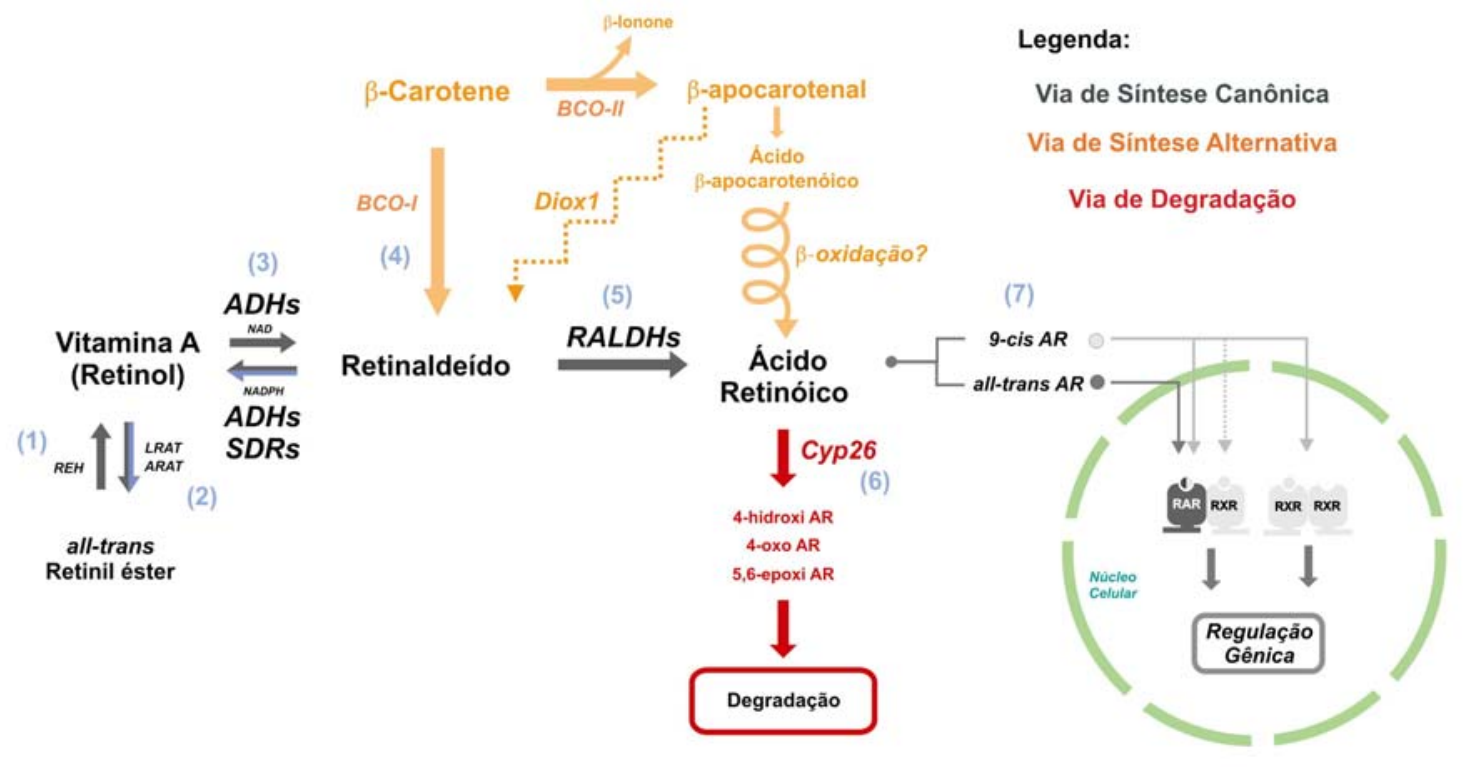

Figura 9. Metabolismo do ácido retinóico (AR). Em preto, a via canônica de síntese do AR. (1) A vitamina A é obtida através da dieta ou convertida a partir de all-trans retinil ésteres pelas retinil éster hidrolases (REH). (2) Alternativamente, a vitamina A pode ser convertida a alltrans retinil éster para armazenamento no fígado. Este processo é catabolizado pelas lecitina-retinol acetiltransferases (LRATs) e pelas acil-CoA-retinol acyltransferases (ARATs). (3) A síntese do retinaldeído ocorre pela oxidação reversível catalisada por álcool desidrogenases (ADHs) ou desidrogenases microsomais de cadeia curta (SDRs) em uma reação dependente de NAD. (4) Retinaldeído também pode ser obtido através da quebra de $\beta$-caroteno pela enzima $\beta$ - $\beta$-caroteno-15,15'-oxigenase (BCO-I). (5) $O$ retinaldeído é oxidado a AR pelas retinaldeído desidrogenases (RALDHs). Em vermelho, a via de degradação do AR. (6) As CYP26s oxidam o AR a diferentes metabólitos como o 4-hidroxi AR, o 4-oxo-AR e o 5,6-epoxi AR. Estes compostos são subsequentemente degradados até se tornarem inativos. (7) Após a síntese do AR, este atua no núcleo da célula se ligando aos receptores nucleares RAR e RXR, que regulam a expressão gênica. 
A importância desta família de enzimas é consistente com o fato de que as vias biossintéticas de todos os retinóides convergem no retinaldeído (Figura 9). Ao contrário das ADHs, RALDHs possuem padrões de expressão bem definidos e bastante dinâmicos (Hsu, et al., 2000; Mic, et al., 2000; Sirbu, et al., 2005). Tais padrões de expressão coincidem fortemente com as regiões de resposta a AR, que foram identificadas através do uso de elementos responsivos a AR ligados a genesrepórter em animais transgênicos (Rossant, et al., 1991). Portanto, o ponto crítico de controle da disponibilidade do AR é a conversão irreversível de retinaldeído para AR pelas RALDHs, sendo que a síntese e subsequente sinalização pelo AR pode ser ativada apenas com a liberação de expressão desta família de enzimas.

Até agora foram identificadas em vertebrados três RALDHs: RALDH1 (ou ALDH1A1), RALDH2 (ou ALDH1A2) e RALDH3 (ou ALDH1A3). Entre elas, a RALDH2 é o parálogo de maior importância durante o desenvolvimento embrionário. Esta enzima é a primeira RALDH a ser expressa durante o desenvolvimento de galinhas e camundongos, sendo que a expressão é iniciada durante a gastrulação (Niederreither, et al., 1997). O transcrito da RALDH2 é encontrado em altos níveis no mesênquima de embriões de galinhas e camundongos, com um território bem delimitado que é iniciado abruptamente no primeiro somito e diminui gradativamente na região posterior do embrião (Hochgreb, et al., 2003). A enzima inicialmente não está presente na região anterior do embrião, com exceção de um pequeno domínio de expressão no dobra da cabeça. Eventualmente, a RALDH2 é também expressa no coração, rins, sistema nervoso e membros em desenvolvimento, o que ressalta a importância da sinalização por AR em diversos órgãos e tecidos (Niederreither, et al., 1997; Moss, et al., 1998; Begemann, et al., 2001; Mic, et al., 2004).

A importância da RALDH2 no desenvolvimento embrionário é ressaltada pelo fenótipo do camundongo knockout para este gene. Embriões desta linhagem apresentam a maioria dos defeitos encontrados em embriões submetidos à restrição de vitamina A. Estes defeitos incluem dilatação do tubo cardíaco, ausência de veias e artérias extraembrionárias, redução dos brotos dos membros, ausência dos arcos branqueais posteriores, malformações craniofaciais diversas e trincamento no euxo AP. Este fenótipo pode ser parcialmente resgatado com a administração de AR para as mães de camundongos knockout (Niederreither, et al., 1999). 
Recentemente, estudos de bioinformática realizados por Castillo e colaboradores (não publicado) demonstram que o gene da RALDH2 possui um grande número de elementos cis-regulatórios putativos conservados durante a evolução. A clonagem de um destes elementos regulatórios frente ao gene-reporter GFP induziu expressão na placa do teto e nos interneurônios dorsais do tubo neural de mamíferos, aves e anfíbios. Esta descoberta é consistente com a idéia de que o gene da RALDH2 possui um sistema de regulação modular, onde múltiplos elementos cis-regulatórios controlam a disponibilidade de AR em diferentes tecidos durante o desenvolvimento embrionário. Desta forma, é possível postular que alterações temporais e topológicas na disponibilidade do AR ao longo da evolução, e as consequentes inovações morfológicas relacionadas a estas mudanças, estão diretamente ligada à modificações nas regiões regulatórias do gene da RALDHs em geral e da RALDH2 em particular.

\subsubsection{Vias de degradação do ácido retinóico}

A degradação do AR é mediada pelas CYP26s, uma classe de enzimas do citrocromo P450. As CYP26s oxidam all-trans-AR em uma variedade de metabólitos, como 4-oxo-AR, 4-hydroxy-AR e 5,6-epoxi-AR (Chithalen, et al., 2002). Estes compostos podem em algumas circunstâncias ativar RAR e até mesmo resgatar fenótipos de embriões gerados por codornas submetidas à dieta com ausência de vitamina A (Idres, et al., 2002; Reijntjes, et al., 2003). No entanto, várias evidências sugerem fortemente que a oxidação do AR pela CYP26 tem a função de proteger tecidos dos efeitos do AR.

Uma destas evidências foi obtida através de estudos com silenciamento do gene da CYP26A1. Camundongos knockout para este gene possuem um fenótipo letal que inclui defeitos de padronização do romboencéfalo, spina bifida e redução da cauda (Abu-Abed, et al., 2001). O estudo não investigou a causa específica deste fenótipo, que poderia estar ligada tanto à acumulação dos substratos da CYP26A1 como à falta de seus produtos. Esta questão foi respondida por Niederreither e colaboradores (2002), que cruzaram os animais knockout para 
CYP26A1 com animais knockout para RALDH2. Os animais com genótipo CYP26A1-/- RALDH2 +/- possuem defeitos muito mais tênues que os animais CYP26A1-/-, o que mostra que a redução na produção de AR resgatou parcialmente a ausência da CYP26A1. Estes resultados suportam a idéia de que a enzima CYP26A1 é um agente protetor responsável por extinguir o sinal gerado pelo AR (Swindell, et al., 1999; Niederreither, et al., 2002).

O padrão de expressão das CYP26s é bastante dinâmico e complexo. Três CYP26s foram caracterizadas em vertebrados: CYP26A1, CYP26B1 e CYP26C1. Em amniotos, A CYP26A1 é expressa em um padrão complementar ao da RALDH2. Ela começa a ser expressa no mesmo momento que a RALDH2, porém na neuroectoderme anterior do embrião, onde estão localizados os precursores do diencéfalo e o telencéfalo. Eventualmente a expressão se restringe às pregas neurais anteriores, rombômeros, e olhos. Na região posterior do embrião há outro domínio de expressão de CYP26A1, localizado no broto da cauda e ao redor do blastóporo (Abu-Abed, et al., 2001; MacLean, et al., 2001).

As CYP26s são fortemente reguladas por all-trans-AR. A rápida indução da CYP26 por AR ocorre através de um elemento cis-regulatório responsivo ao $A R$ localizado na região 5 ' do gene. O tratamento de embriões com AR aumenta drasticamente a quantidade de transcritos das CYP26s (Kudoh, et al., 2002). Isto sugere um mecanismo de controle transcripcional, onde a concentração do AR na célula ativa a expressão de CYP26 via RAR e RXR, que diretamente controlam o nível de expressão da enzima para ajustar o nível de AR presente no meio intracelular.

\subsubsection{RAR e RXR: os receptores do ácido retinóico}

Após a síntese, o AR funciona de forma tanto autócrina como parácrina, cruzando membranas celulares para se ligar e ativar RARs e RXRs. RAR e RXR são receptores que funcionam como fatores de transcrição, podendo se ligar aos elementes responsivos a $A R$ que estão presentes nas regiões regulatórias de diversos genes (Chambon, 1996). RAR e RXRs possuem também ampla 
distribuição tecidual, o que sugere que a maioria das células embrionárias dos vertebrados podem responder ao AR (Dolle, et al., 1994; Dreyer e EllingerZiegelbauer, 1996).

RAR e RXRs são proteínas de estruturas semelhantes: na região aminoterminal há um domínio de ativação transcricional, seguido do domínio de ligação ao DNA (DNA binding domain) no centro da cadeia peptídica. O domínio de dimerização, o domínio de ligação com o ligante e a superfície de interação com coreguladores potenciais estão na região C-terminal (Chambon, 1996). Na ausência do $A R$, o heterodímero $R A R / R X R$ se encontra ligado a elementos de resposta ao AR no DNA, associado a co-repressores que induzem silenciamento transcripcional pela deacetilação de histonas e compactação de cromatina. A ligação do AR ao domínio de ligação com o ligante induz uma mudança de conformação que causa a liberação dos correpressores e aumenta a afinidade com coativadores. Os coativadores ativam processos de acetilação de histonas que resultam na abertura da cromatina e ativação de expressão gênica (Aranda e Pascual, 2001; Germain, et al., 2002).

Existem três variantes de RAR (RAR $\alpha, R A R \beta$ e RARy), atuando em conjunto com três variantes de RXR (RXRa, RXR e RXRY). Estudos de mapeamento do padrão de expressão de RARs e RXRs foram realizados em embriões de camundongo e galinha. Em 7.5 dpc, a expressão de RARa, RARy e RXRa é ubiqua, enquanto que RARß é expresso na mesoderme lateral. Durante a neurulação, há a restrição da expressão de RARY para a região anterior do embrião. No entanto, RARa, RARy, RXRa, assim como RXRY, são expressos na mesoderme précardíaca, o que confirma que estas células são responsivas a $A R$ e sugere o envolvimento de retinóides na formação do coração (Dolle, et al., 1994; Cui, et al., 2003).

\subsection{Sinalização pelo Ácido Retinóico no Desenvolvimento Cardíaco}

O AR possui múltiplas funções no desenvolvimento cardiovascular. A importância deste morfógeno na formação do coração foi inicialmente identificada 
através de tratamentos que visavam aumentar ou reduzir a disponibilidade de AR nos tecidos do embrião (Osmond, et al., 1991; Stainier e Fishman, 1992). Tais experimentos demonstraram que uma variedade de eventos envolvidos na embriogenia cardíaca são dependentes ou influenciados por AR. Atualmente, sabese que o AR está implicado em processos como a delimitação do campo cardíaco, formação das câmaras cardíacas, proliferação do miocárdio, desenvolvimento da circulação coronariana e valvulogênese (Heine, et al., 1985; Drysdale, et al., 1997; Moss, et al., 1998; Chazaud, et al., 1999; Niederreither, et al., 1999; Perez-Pomares, et al., 2002; Hochgreb, et al., 2003; Stuckmann, et al., 2003). Nesta seção, abordase especificamente o papel da sinalização pelo AR na formação das câmaras cardíacas.

\subsubsection{O AR na segmentação do coração de vertebrados}

Como visto anteriormente, o estabelecimento da polaridade AP é essencial para que o embrião organize o seu coração tubular em segmentos de influxo (posteriores) e de efluxo (anteriores). A correta organização desses segmentos possibilita a inserção efetiva do coração na circulação, conectando seus segmentos de influxo com o sistema venoso, e seus segmentos de efluxo com o sistema arterial (Hochgreb, et al., 2003).

As primeiras evidências do papel do AR na padronização AP do coração foram obtidas através de estudos de manipulação da sinalização por AR em embriões de galinha. Yutzey e colaboradores (1995) realizaram tratamentos com alltrans AR em diferentes estágios do desenvolvimento e analisaram o fenótipo obtido, utilizando AMHC1 como marcador do fenótipo atrial. Tratamento com AR no estágio HH5 resultou em expansão do domínio de $\mathrm{AMHC1}$, enquanto que a mesma dose após o estágio HH8 não causou nenhuma alteração na quantidade de tecido atrial. Portanto, após este estágio os precursores cardíacos parecem estar determinados com o destino sinoatrial (Yutzey e Bader, 1995).

Em 2000, Patwardhan e colaboradores realizaram inversões cirúrgicas do campo cardíaco e analisaram os efeitos da inversão no coração com o uso de 
AMHC1 (marcador atrial) e VMHC1 (marcador ventricular). A rotação de $180^{\circ}$ do campo cardíaco nos estágios $\mathrm{HH} 4, \mathrm{HH} 5$ e $\mathrm{HH} 6$ resultaram em embriões com disposição normal de átrios e ventrículos, demonstrando que no momento do transplante os tecidos ainda não estavam determinados com as suas identidades atriais e ventriculares. No entanto, se o transplante for realizado no estágio $\mathrm{HH} 8$, o embrião apresenta tecido ventricular na região posterior e tecido atrial na região anterior, o que indica que no momento do transplante os domínios atriais e ventriculares do campo cardíaco já estavam determinados (Patwardhan, et al., 2000). Em 2003, Hochgreb e colaboradores realizaram uma série de tratamentos com AR e BMS493, um pan-antagonista do RAR, em embriões de galinha de diferentes estágios. Os resultados obtidos demonstraram que o comprometimento dos precursores cardiacos com os seus destinos de influxo e efluxo ocorre entre os estágios $\mathrm{HH} 7$ e $\mathrm{HH} 8$.

Resultados semelhantes são observados em embriões de camundongo. Um pulso de AR exógeno administrado em camundongas grávidas de embriões com 7.5 dpc resulta em embriões com coração com dominância atrial e perda quase completa de tecido ventricular. No entanto, se o AR for administrado em $8.5 \mathrm{dpc}$, não há efeitos na morfogenia cardíaca, o que sugere que o comprometimento com fenótipos de influxo e efluxo ocorre entre 7.5 e 8.5 dpc (Chazaud, et al., 1999). De forma semelhante, manipulação da sinalização por AR parece perturbar o estabelecimento da polaridade AP em peixes. Administração de AR em embriões de peixe (Danio rerio) causa deleção de câmaras cardíacas de uma forma dose dependente, sendo que as câmaras de efluxo são mais afetadas que as câmaras de influxo. Além disso, os dois mutantes de D. rerio para RALDH2, neckless e no-fin, possuem defeitos cardíacos, sugerindo um papel importante desta enzima na padronização AP cardíaca (Begemann, et al., 2001; Grandel, et al., 2002).

De fato, Hochgreb e colaboradores (2003) identificaram a RALDH2 como agente responsável pela geração do sinal de $A R$ durante o processo de padronização AP do coração. A ação do AR neste processo ocorre em duas etapas. Inicialmente os precursores são especificados aos seus respectivos destinos AP através do AR que difunde a partir do domínio posterior de expressão de RALDH2 (Hochgreb, et al., 2003). No momento da especificação, RALDH2 é expresso no mesoderma posterior, enquanto que CYP26 é produzida no mesoderma anterior do 
embrião (Swindell, et al., 1999). A distribuição destas enzimas gera um gradiente de concentração de AR que afeta diferencialmente os precursores cardíacos.

No início da gastrulação de embriões de galinha, várias centenas de micrômetros separam o campo cardíaco das células mesodérmicas que expressam RALDH2. Essa distância se reduz progressivamente até que no estágio HH6 o limite anterior da expressão de RALDH2 coincide com o limite posterior do campo cardíaco. Tal evidência, aliada a estudos de manipulação da sinalização do AR, sugere fortemente que o $A R$ que difunde da mesoderme posterior está especificando as células cardíacas posteriores a um destino sinoatrial (Hochgreb, et al., 2003) (Figura 10A, B e E).

A determinação irreversível dos destinos AP dos precursores cardíacos ocorre entre os estágios $\mathrm{HH} 7$ e HH8 em embriões de galinha e possivelmente exige concentrações de AR mais altas do que as disponibilizadas por difusão. De fato, é provável que o surgimento de um mecanismo morfogenético ao longo da evolução tenha resultado em maior disponibilidade de $A R$ na região posterior do campo cardíaco, no momento em que o destino dos precursores é determinado. O aumento nos níveis de AR é causado por uma onda caudo-rostral de RALDH2 que percorre o campo cardíaco entre os estágios HH7-HH8 (Figura 10C, D e F). Essa onda caudorostral possibilita que os precursores posteriores produzam o seu próprio AR no momento chave do comprometimento AP do campo cardíaco. Portanto, podemos concluir que o comprometimento dos precursores cardíacos em compartimentos de influxo e efluxo ocorre em dois passos: inicialmente com efeito parácrino do AR produzido no mesoderma posterior e mais tardiamente com efeito autócrino das células cardíacas posteriores, que passam a sintetizar AR através da formação da onda de RALDH2 (Hochgreb, et al., 2003; Simoes-Costa, et al., 2005).

\subsubsection{O modelo de duas etapas e a origem das câmaras cardíacas}

O modelo de duas etapas também sugere um programa experimental para investigar a filogenia das câmaras cardíacas. Os resultados observados em aves e mamíferos indicam que os precursores cardíacos têm a sua identidade determinada 
quando a onda de RALDH2 envolve a parte posterior do campo cardíaco. Em termos evolutivos, isto implica que o surgimento das câmaras cardíacas provavelmente exigiu uma mudança da topologia entre os fatores cardiomiogênicos e as enzimas responsáveis pela síntese do AR (Simoes-Costa, et al., 2005). De acordo com esta hipótese, surgimento de um gradiente de concentração de AR na região do campo cardíaco teria sido fundamental para a transição entre a bombas peristáltica ancestral e um coração com câmaras.
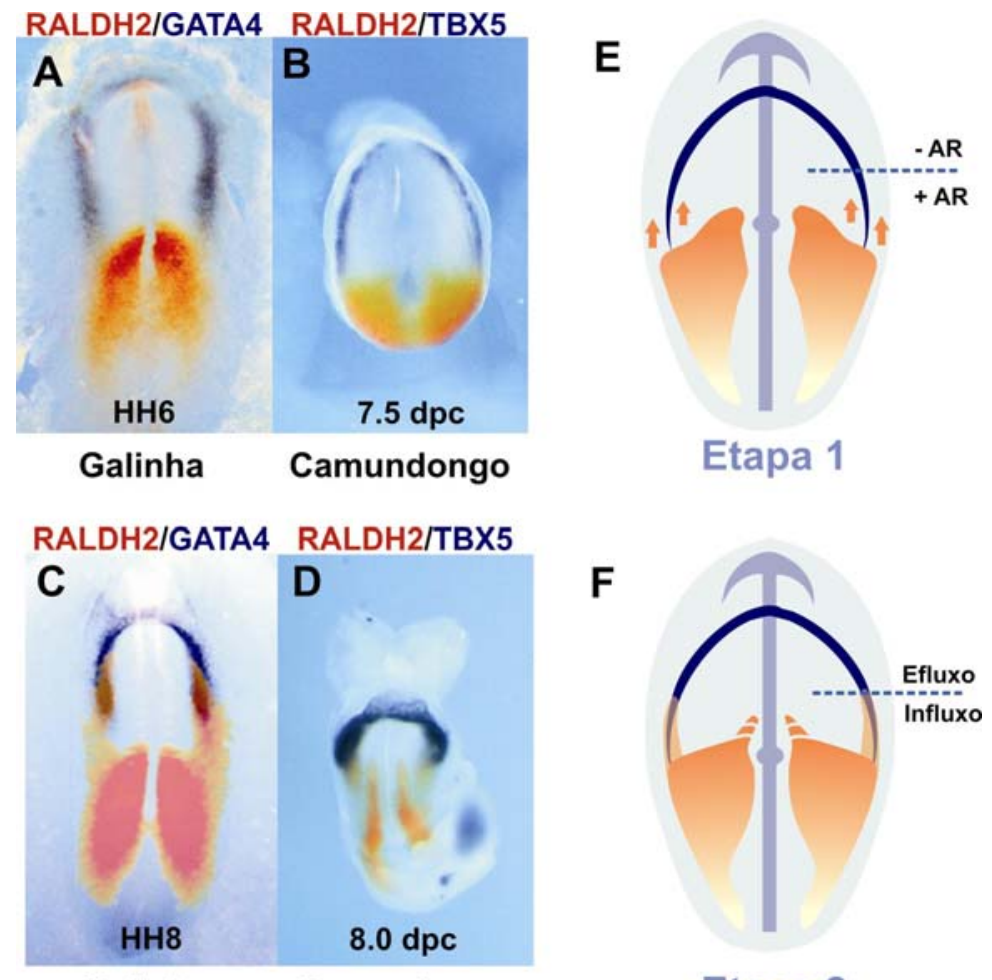

Galinha Camundongo

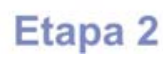

Figura 10. Modelo de duas etapas para a padronização antero-posterior (AP) do coração. (A, B) Dupla hibridação in situ para RALDH2 (alaranjado) e para o marcador cardíaco GATA4 (azul) em embriões de galinha (A) e camundongo (B). (C, D) Formação da onda de RALDH2 em embriões de galinha $(C)$ e camundongo. (E, F) Esquema representando o modelo de duas etapas. Inicialmente, os precursores cardíacos posteriores recebem ácido retinóico (AR) que difunde da mesoderme lateral que expressa RALDH2 (E). Posteriormente, estes precursores adquirem a capacidade de sintetizar AR, o que forma uma onda caudo-rostral de RALDH2 que percorre o campo cardíaco (F). 
De acordo com esta hipótese, as câmaras cardíacas se originaram a partir de re-organização morfogenética de células semelhantes a cardiomiócitos ventriculares, ao invés da adição de módulos genéticos responsáveis pela formação de câmaras compostas por tipos celulares completamente novos. Isto é consistente com a noção de que o coração vertebrado não evoluiu a partir da adição sequencial de câmaras (Figura 11A), como proposto por Bourne (1982). Esta proposta, que prevê o recrutamento de novos grupos de precursores para cada compartimento do coração, é pouco provável devido à baixa eficiência dos intermediários (SimoesCosta, et al., 2005). Como alternativa, é possível que o coração vertebrado tenha surgido como um órgão de múltiplos compartimentos, criados simultaneamente por um evento de padronização como a sinalização pelo AR (Figuras 11B e C) Este evento de padronização teria repardio os precursores de uma bomba circulatória ancestral em territórios com diferentes portencialidades. Tais territórios eventualmente teriam dado origem aos diferentes segmentos observados no coração com câmaras (Simoes-Costa, et al., 2005). Portanto, o modelo de duas etapas pode ser utilizado para investigar a abrupta transição de vaso peristáltico a coração com câmaras, observada no surgimento dos vertebrados.

Para testar a hipótese de que a onda caudo-rostral foi importante para a origem do coração, torna-se necessário estabelecer se as duas etapas do modelo encontram-se conservadas em outros vertebrados. Além disso, é necessário investigar as relações topológicas entre a produção de AR e os precursores das bombas circulatórias em cordados invertebrados. Desta forma, neste trabalho foi investigado o papel do AR no desenvolvimento cardíaco tanto em modelos animais já estabelecidos na biologia do desenvolvimento (Gallus gallus, Xenopus laevis, Danio rerio), como em organismos que ocupam posições relevantes na linhagem filogenética dos cordados (Petromyzon marinus, Branchiostoma floridae). O objetivo foi verificar se a relação topológica entre a fonte de produção de AR e o campo cardíaco encontrado em amniotos é mantida nos vertebrados basais. Além disso, também foi analisada a sinalização pelo AR durante a formação da bomba circulatória do cordado invertebrado $B$. floridae, em buscas de pistas sobre o envolvimento do AR na gênese das bombas circulatórias dos cordados basais. Os resultados obtidos indicam que a onda caudo-rostral de RALDH2 está presente em todos os vertebrados estudados, o que sugere fortemente que o mecanismo de 
duas etapas não é uma particularidade dos amniotos, e sim um mecanismo ancestral fundamental na formação do coração vertebrado. Isto corrobora a hipótese de que a sinalização pelo AR foi fundamental para a origem evolutiva do coração vertebrado.

(A)

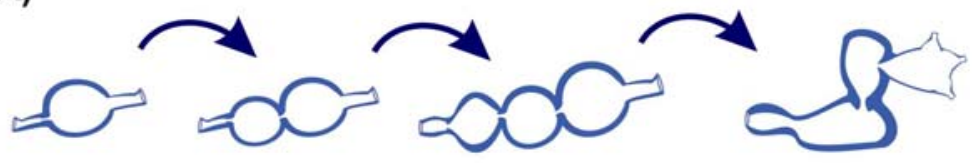

(B)

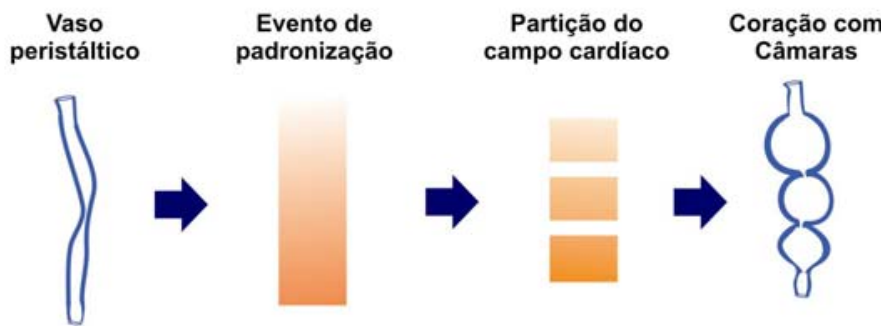

(C)

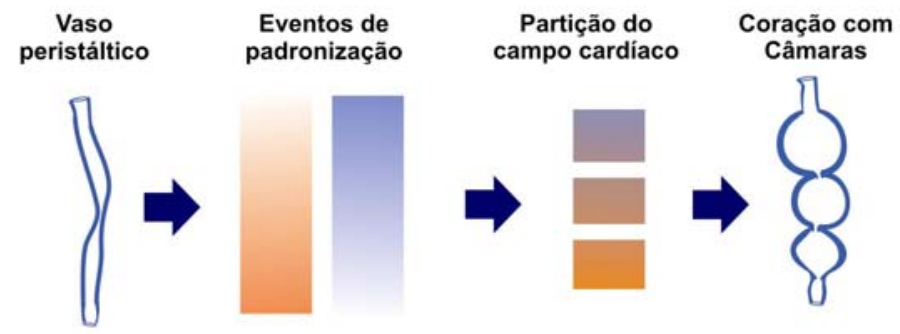

Figura 11. Hipóteses para a origem do coração vertebrados.(A) Evolução do coração por adição sequencial de câmaras. De acordo com esta hipótese, novos módulos foram adicionados à bomba ancestral ao longo da evolução para formar um órgão multicamerado. (B e C) Evolução do coração mediada por evento(s) de padronização, onde a divisão do campo cardíaco em regiões com diferentes características por um ou mais morfógenos possibilitou a transição abrupta entre o vaso peristáltico ancestral e o coração vertebrado. 
6 CONCLUSÕES 
- No peixe teleósteo $D$. rerio e no anfíbio $X$. laevis, a formação da onda caudorostral de expressão da enzima RALDH2 ocorre em períodos compatíveis com o modelo de de padronização AP caradíaco descrito para amnitoos por Hochgreb e colaboradores (2003). Este fato, aliado às de evidências que apontam para o envolvimento do ácido retinóico no desenvolvimento cardíaco destes animais, aponta para a conservação do modelo de duas etapas em nos vertebrados.

- A identificação e mapeamento da expressão do ortólogo da RALDH2 em $P$. marinus confirma que a onda caudo-rostral é um mecanismo ancestral dos vertebrados. A caracterização dos padrões de expressão dos genes MEF2A/C/D e TBX20 em lampréias sugere que a onda caudo-rostral está envolvida no desenvolvimento caradíaco destes vertebrados basais.

- O cefalocordado anfioxo apresenta seis parálogos das enzimas da classe ALDH1, sendo que uma delas, a ALDH1A, pode ser considerada ortóloga à RALDH2. Esta enzima é expressa apenas na região posterior de embriões de anfioxo, sendo que não há a formação de uma onda caudo-rostral de expressão. Além disso, a formação da bomba circulatória deste animal ocorre sem o envolvimento do fator de transcrição MEF2C, que está presente do desenvolvimento de bombas de protostômios e deuterostômios.

- O modelo de duas etapas, que descreve a partição do campo cardíaco em regiões de influxo e efluxo por uma onda de expressão caudo-rostral da enzima RALDH2, é uma particularidade dos vertebrados. A onda caudorostral de RALDH2 é um padrão de expressão mais antigo, observado nos tunicados. Portanto, os resultados obtidos neste trabalham corroboram a hipótese de que a onda caudo-rostral de RALDH2 surgiu nos ancestral de tunicados e vertebrados, tendo sido cooptada nos vertebrados para padronizar o campo cardíaco, gerando territórios de células com diferentes potencialidades e possibilitando a origem evolutiva das câmaras cardíacas. 
REFERÊNCIAS BIBLIOGRÁFICAS 
${ }^{2}$ Abu-Abed S, Dolle P, Metzger D, Beckett B, Chambon P, Petkovich M. The retinoic acid-metabolizing enzyme, CYP26A1, is essential for normal hindbrain patterning, vertebral identity, and development of posterior structures. Genes Dev. 2001;15(2):226-40.

Alsan BH, Schultheiss TM. Regulation of avian cardiogenesis by Fgf8 signaling. Development. 2002;129(8):1935-43.

Aranda A, Pascual A. Nuclear hormone receptors and gene expression. Physiol Rev. $2001 ; 81(3): 1269-304$.

Begemann G, Schilling TF, Rauch GJ, Geisler R, Ingham PW. The zebrafish neckless mutation reveals a requirement for raldh2 in mesodermal signals that pattern the hindbrain. Development. 2001;128(16):3081-94.

Berdougo E, Coleman H, Lee DH, Stainier DY, Yelon D. Mutation of weak atrium/atrial myosin heavy chain disrupts atrial function and influences ventricular morphogenesis in zebrafish. Development. 2003;130(24):6121-9.

Black BL, Olson EN. Transcriptional control of muscle development by myocyte enhancer factor-2 (MEF2) proteins. Annu Rev Cell Dev Biol. 1998;14(1)167-96.

Bodmer R. The gene tinman is required for specification of the heart and visceral muscles in Drosophila. Development. 1993;118(3):719-29.

Bourne GH. Hearts and Heart-Like Organs. New York: Academic Press; 1980.

Brand T. Heart development: molecular insights into cardiac specification and early morphogenesis. Dev Biol. 2003;258(1):1-19.

Bruneau BG. Transcriptional regulation of vertebrate cardiac morphogenesis. Circ Res. 2002;90(1):509-19.

Brusca RC, Brusca GJ. Invertebrates. 2nd ed. Sunderland, Mass.: Sinauer Associates; 2003.

Buckingham M, Meilhac S, Zaffran S. Building the mammalian heart from two sources of myocardial cells. Nat Rev Genet. 2005;6(11):826-35.

Burggren W, Johansen K. Ventricular Hemodynamics in the Monitor Lizard VaranusExanthematicus - Pulmonary and Systemic Pressure Separation. J Exp Biol. 1982;96(FEB):343-54.

Burggren WW. Cardiac design in lower vertebrates: what can phylogeny reveal about ontogeny? Experientia. 1988;44(11-12):919-30.

\footnotetext{
${ }^{2}$ De acordo com:

International Committee of Medical Journal Editors. Uniform requirements for manuscripts submitted to Biomedical Journal: sample references. Available from: http://www.icmje.org [2007 May 22].
} 
Cai CL, Liang X, Shi Y, Chu PH, Pfaff SL, Chen J, et al. Isl1 identifies a cardiac progenitor population that proliferates prior to differentiation and contributes a majority of cells to the heart. Dev Cell. 2003;5(6):877-89.

Carter GS. Structure and habit in vertebrate evolution. 1 ed. London: Sidgwick \& Jackson; 1967.

Castro RA. Um modelo de padronização das camaras cardíacas em Dario rerio. Dissertação de Mestrado. São Paulo: USP; 2008.

Chambon P. A decade of molecular biology of retinoic acid receptors. Faseb J. 1996;10(9):940-54.

Chazaud C, Chambon P, Dolle P. Retinoic acid is required in the mouse embryo for left-right asymmetry determination and heart morphogenesis. Development. 1999;126(12):2589-96.

Chen Y, Pollet N, Niehrs C, Pieler T. Increased XRALDH2 activity has a posteriorizing effect on the central nervous system of Xenopus embryos. Mech Dev. 2001;101(1-2):91-103.

Chithalen JV, Luu L, Petkovich M, Jones G. HPLC-MS/MS analysis of the products generated from all-trans-retinoic acid using recombinant human CYP26A. J Lipid Res. 2002;43(7):1133-42.

Christoffels VM, Habets PE, Franco D, Campione M, de Jong F, Lamers WH, et al. Chamber formation and morphogenesis in the developing mammalian heart. Dev Biol. 2000;223(2):266-78.

Cleaver OB, Patterson KD, Krieg PA. Overexpression of the tinman-related genes XNkx-2.5 and XNkx-2.3 in Xenopus embryos results in myocardial hyperplasia. Development. 1996;122(11):3549-56.

Conway Morris S. The Cambrian "explosion": slow-fuse or megatonnage? Proc Natl Acad Sci U S A. 2000;97(9):4426-9.

Coolen M, Sauka-Spengler T, Nicolle D, Le-Mentec C, Lallemand Y, Da Silva C, et al. Evolution of axis specification mechanisms in jawed vertebrates: insights from a chondrichthyan. PLoS ONE. 2007;2(4):e374.

Cravo RM. Controle da expressão do gene ALDH1A2 (RALDH2) durante o desenvolvimento: uma abordagem filogenética. Tese de Doutorado. São Paulo: USP; 2008.

Cui J, Michaille JJ, Jiang W, Zile MH. Retinoid receptors and vitamin A deficiency: differential patterns of transcription during early avian development and the rapid induction of RARs by retinoic acid. Dev Biol. 2003;260(2):496-511. 
Damas H. Recherches sur le développement de Lampetra fluviatilis L. - contribution à l'étude de la cephalogénèse des vertébrés. Arch Biol. 1944;55(1):1-289.

Davidson B, Levine M. Evolutionary origins of the vertebrate heart: Specification of the cardiac lineage in Ciona intestinalis. Proc Natl Acad Sci $U S A$. 2003;100(20):11469-73.

Davidson $\mathrm{EH}$. The regulatory genome : gene regulatory networks in development and evolution. Amsterdam ; Boston: Elsevier/Academic Press; 2006.

de la Cruz MV, Markwald RR. Living morphogenesis of the heart. Cambridge, EUA: Birkhäuser; 1998.

DeHaan RL. Migration patterns of precardiac mesoderm in early chick embryo. Exp Cell Res. 1963;29(1)544-60.

Delsuc $F$, Brinkmann $H$, Chourrout D, Philippe $H$. Tunicates and not cephalochordates are the closest living relatives of vertebrates. Nature. 2006;439(7079):965-8.

Denkers N, Garcia-Villalba P, Rodesch CK, Nielson KR, Mauch TJ. FISHing for chick genes: Triple-label whole-mount fluorescence in situ hybridization detects simultaneous and overlapping gene expression in avian embryos. Dev Dyn. 2004;229(3):651-7.

DeRuiter MC, Poelmann RE, VanderPlas-de Vries I, Mentink MM, Gittenberger-de Groot AC. The development of the myocardium and endocardium in mouse embryos. Fusion of two heart tubes? Anat Embryol (Berl). 1992;185(5):461-73.

Dodou E, Verzi MP, Anderson JP, Xu SM, Black BL. Mef2c is a direct transcriptional target of ISL1 and GATA factors in the anterior heart field during mouse embryonic development. Development. 2004;131(16):3931-42.

Dolle $\mathrm{P}$, Fraulob V, Kastner $\mathrm{P}$, Chambon $\mathrm{P}$. Developmental expression of murine retinoid X receptor (RXR) genes. Mech Dev. 1994;45(2):91-104.

Dreyer C, Ellinger-Ziegelbauer $\mathrm{H}$. Retinoic acid receptors and nuclear orphan receptors in the development of Xenopus laevis. Int J Dev Biol. 1996;40(1):255-62.

Drysdale TA, Patterson KD, Saha M, Krieg PA. Retinoic acid can block differentiation of the myocardium after heart specification. Dev Biol. 1997;188(2):205-15.

Duester G. Families of retinoid dehydrogenases regulating vitamin A function: production of visual pigment and retinoic acid. Eur J Biochem. 2000;267(14):431524.

Duester G. Genetic dissection of retinoid dehydrogenases. Chem Biol Interact. 2001;130-132(1-3):469-80. 
Fange R. The circulatory system. In: Hardisty MW, Potter IC, editors. The biology of lampreys. New York: Academic Press; 1972. p. 287-306.

Farrell A. Evolution of cardiovascular systems: insights into ontogeny. In: Burggren W, Keller BB, editors. Development of cardiovascular systems. New York: Cambridge University Press; 1997. p. 360.

Fishman MC, Chien KR. Fashioning the vertebrate heart: earliest embryonic decisions. Development. 1997;124(11):2099-117.

Fishman MC, Olson EN. Parsing the heart: genetic modules for organ assembly. Cell. 1997;91(2):153-6.

Forouhar AS, Liebling M, Hickerson A, Nasiraei-Moghaddam A, Tsai HJ, Hove JR, et al. The embryonic vertebrate heart tube is a dynamic suction pump. Science. 2006;312(5774):751-3.

Gannon M, Bader D. Initiation of cardiac differentiation occurs in the absence of anterior endoderm. Development. 1995;121(8):2439-50.

Gans C, Northcutt RG. Neural Crest and the Origin of Vertebrates: A New Head. Science. 1983;220(4594):268-73.

Garcia-Martinez V, Schoenwolf GC. Primitive-streak origin of the cardiovascular system in avian embryos. Dev Biol. 1993;159(2):706-19.

Germain P, lyer J, Zechel C, Gronemeyer H. Co-regulator recruitment and the mechanism of retinoic acid receptor synergy. Nature. 2002;415(6868):187-92.

Grandel H, Lun K, Rauch GJ, Rhinn M, Piotrowski T, Houart C, et al. Retinoic acid signalling in the zebrafish embryo is necessary during pre-segmentation stages to pattern the anterior-posterior axis of the CNS and to induce a pectoral fin bud. Development. 2002;129(12):2851-65.

Hall BG. Phylogenetic Trees Made Easy. 3 ed. New York: Sinauer Associates 2007.

Hamburguer V, Hamilton HL. A series of normal stages in the development of the chick embryo. J Morphol. 1951;88(49-92.

Harrison EH. Mechanisms of digestion and absorption of dietary vitamin A. Annu Rev Nutr. 2005;25(87-103.

Harvey RP. NK-2 homeobox genes and heart development. Dev Biol. 1996;178(2):203-16.

Harvey RP. Patterning the vertebrate heart. Nat Rev Genet. 2002;3(7):544-56.

Heine UI, Roberts AB, Munoz EF, Roche NS, Sporn MB. Effects of retinoid deficiency on the development of the heart and vascular system of the quail embryo. Virchows Arch B Cell Pathol Incl Mol Pathol. 1985;50(2):135-52. 
Hirakow R. The vertebrate heart in phylogenetic relation to the prochordates. Fortschr Zool 1985;1(30):367-9.

Hochgreb T, Linhares VL, Menezes DC, Sampaio AC, Yan CY, Cardoso WV, et al. A caudorostral wave of RALDH2 conveys anteroposterior information to the cardiac field. Development. 2003;130(22):5363-74.

Holland LZ, Holland ND. Expression of AmphiHox-1 and AmphiPax-1 in amphioxus embryos treated with retinoic acid: insights into evolution and patterning of the chordate nerve cord and pharynx. Development. 1996;122(6):1829-38.

Holland LZ, Yu JK. Cephalochordate (amphioxus) embryos: procurement, culture, and basic methods. Methods Cell Biol. 2004;74(1)195-215.

Holland ND, Venkatesh TV, Holland LZ, Jacobs DK, Bodmer R. AmphiNk2-tin, an amphioxus homeobox gene expressed in myocardial progenitors: insights into evolution of the vertebrate heart. Dev Biol. 2003;255(1):128-37.

Horb ME, Thomsen GH. Tbx5 is essential for heart development. Development. 1999;126(8):1739-51.

Hsu LC, Chang WC, Yoshida A. Mouse type-2 retinaldehyde dehydrogenase (RALDH2): genomic organization, tissue-dependent expression, chromosome assignment and comparison to other types. Biochim Biophys Acta. 2000;1492(1):289-93.

Icardo JM, Guerrero A, Duran AC, Domezain A, Colvee E, Sans-Coma V. The development of the sturgeon heart. Anat Embryol (Berl). 2004;208(6):439-49.

Idres N, Marill J, Flexor MA, Chabot GG. Activation of retinoic acid receptordependent transcription by all-trans-retinoic acid metabolites and isomers. J Biol Chem. 2002;277(35):31491-8.

Irie T, Kajiwara S, Kojima N, Senoo H, Seki T. Retinal is the essential form of retinoid for storage and transport in the adult of the ascidian Halocynthia roretzi. Comp Biochem Physiol B Biochem Mol Biol. 2004;139(4):597-606.

Jefferies RPS. The Ancestry of the vertebrates. London: BM(NH); 1986.

Jiang $Y$, Drysdale TA, Evans T. A role for GATA-4/5/6 in the regulation of Nkx2.5 expression with implications for patterning of the precardiac field. Dev Biol. 1999;216(1):57-71.

Kardong KV. Vertebrates : comparative anatomy, function, evolution. 3 ed. Boston: McGraw-Hill; 2002.

Kaufman $\mathrm{MH}$, Navaratnam $\mathrm{V}$. Early differentiation of the heart in mouse embryos. J Anat. 1981;133(Pt 2):235-46. 
Keegan BR, Feldman JL, Begemann G, Ingham PW, Yelon D. Retinoic acid signaling patterns anterior lateral plate mesoderm. Dev Biol. 2003;259(2):517-.

Keegan BR, Feldman JL, Begemann G, Ingham PW, Yelon D. Retinoic acid signaling restricts the cardiac progenitor pool. Science. 2005;307(5707):247-9.

Keegan BR, Meyer D, Yelon D. Organization of cardiac chamber progenitors in the zebrafish blastula. Development. 2004;131(13):3081-91.

Kelly RG, Brown NA, Buckingham ME. The arterial pole of the mouse heart forms from Fgf10-expressing cells in pharyngeal mesoderm. Dev Cell. 2001;1(3):435-40.

Kimmel CB, Ballard WW, Kimmel SR, Ullmann B, Schilling TF. Stages of embryonic development of the zebrafish. Dev Dyn. 1995;203(3):253-310.

Kirby ML, Waldo KL. Neural crest and cardiovascular patterning. Circ Res. 1995;77(2):211-5.

Kitajima S, Takagi A, Inoue T, Saga Y, . MesP1 and Mesp2 are essential for the development of cardiac mesoderm. Development. 2000;127(3215-26.

Kostetskii I, Jiang Y, Kostetskaia E, Yuan S, Evans T, Zile M. Retinoid signaling required for normal heart development regulates GATA-4 in a pathway distinct from cardiomyocyte differentiation. Dev Biol. 1999;206(2):206-18.

Kriebel ME. Studies on cardiovascular physiology of tunicates. Biol Bull 1968;1(134):434-55

Kudoh T, Wilson SW, Dawid IB. Distinct roles for Fgf, Wnt and retinoic acid in posteriorizing the neural ectoderm. Development. 2002;129(18):4335-46.

Kuo CT, Morrisey EE, Anandappa R, Sigrist K, Lu MM, Parmacek MS, et al. GATA4 transcription factor is required for ventral morphogenesis and heart tube formation. Genes Dev. 1997;11(8):1048-60.

Kuratani S, Horigome N, Hirano S. Developmental morphology of the head mesoderm and reevaluation of segmental theories of the vertebrate head: evidence from embryos of an agnathan vertebrate, Lampetra japonica. Dev Biol. 1999;210(2):381-400.

Kuratani S, Ueki T, Hirano S, Aizawa S. Rostral truncation of a cyclostome, Lampetra japonica, induced by all-trans retinoic acid defines the head/trunk interface of the vertebrate body. Dev Dyn. 1998;211(1):35-51.

Langeland JA, Holland LZ, Chastain RA, Holland ND. An amphioxus LIM-homeobox gene, AmphiLim1/5, expressed early in the invaginating organizer region and later in differentiating cells of the kidney and central nervous system. Int $\mathrm{J}$ Biol Sci. 2006;2(3):110-6. 
Lee RK, Stainier DY, Weinstein BM, Fishman MC. Cardiovascular development in the zebrafish. II. Endocardial progenitors are sequestered within the heart field. Development. 1994;120(12):3361-6.

Lin Q, Schwarz J, Bucana C, Olson EN. Control of mouse cardiac morphogenesis and myogenesis by transcription factor MEF2C. Science. 1997;276(5317):1404-7.

Linask KK, Knudsen KA, Gui YH. N-cadherin-catenin interaction: necessary component of cardiac cell compartmentalization during early vertebrate heart development. Dev Biol. 1997;185(2):148-64.

Lopez-Sanchez C, Climent V, Schoenwolf GC, Alvarez IS, Garcia-Martinez V. Induction of cardiogenesis by Hensen's node and fibroblast growth factors. Cell Tissue Res. 2002;309(2):237-49.

Lubzens E, Lissauer L, Levavi-Sivan B, Avarre JC, Sammar M. Carotenoid and retinoid transport to fish oocytes and eggs: what is the role of retinol binding protein? Mol Aspects Med. 2003;24(6):441-57.

MacLean G, Abu-Abed S, Dolle P, Tahayato A, Chambon P, Petkovich M. Cloning of a novel retinoic-acid metabolizing cytochrome P450, Cyp26B1, and comparative expression analysis with Cyp26A1 during early murine development. Mech Dev. 2001;107(1-2):195-201.

Manner J. Cardiac looping in the chick embryo: a morphological review with special reference to terminological and biomechanical aspects of the looping process. Anat Rec. 2000;259(3):248-62.

Marchetti MN, Sampol E, Bun H, Scoma H, Lacarelle B, Durand A. In vitro metabolism of three major isomers of retinoic acid in rats. Intersex and interstrain comparison. Drug Metab Dispos. 1997;25(5):637-46.

Marletaz F, Holland LZ, Laudet V, Schubert M. Retinoic acid signaling and the evolution of chordates. Int J Biol Sci. 2006;2(2):38-47.

Meilhac SM, Esner M, Kelly RG, Nicolas JF, Buckingham ME. The clonal origin of myocardial cells in different regions of the embryonic mouse heart. Dev Cell. 2004;6(5):685-98.

Mic FA, Molotkov A, Fan X, Cuenca AE, Duester G. RALDH3, a retinaldehyde dehydrogenase that generates retinoic acid, is expressed in the ventral retina, otic vesicle and olfactory pit during mouse development. Mech Dev. 2000;97(1-2):22730.

Mic FA, Molotkov A, Molotkova N, Duester G. Raldh2 expression in optic vesicle generates a retinoic acid signal needed for invagination of retina during optic cup formation. Dev Dyn. 2004;231(2):270-7. 
Mjaatvedt $\mathrm{CH}$, Nakaoka T, Moreno-Rodriguez R, Norris RA, Kern MJ, Eisenberg CA, et al. The outflow tract of the heart is recruited from a novel heart-forming field. Dev Biol. 2001;238(1):97-109.

Mohun TJ, Leong LM, Weninger WJ, Sparrow DB. The morphology of heart development in Xenopus laevis. Dev Biol. 2000;218(1):74-88.

Moller PC, Philpott CW. The circulatory system of Amphioxus (Branchiostoma floridae). I. Morphology of the major vessels of the pharyngeal area. J Morphol. 1973;139(4):389-406.

Molotkov A, Deltour L, Foglio MH, Cuenca AE, Duester G. Distinct retinoid metabolic functions for alcohol dehydrogenase genes Adh1 and Adh4 in protection against vitamin A toxicity or deficiency revealed in double null mutant mice. J Biol Chem. 2002;277(16):13804-11.

Moore SA, Baker HM, Blythe TJ, Kitson KE, Kitson TM, Baker EN. Sheep liver cytosolic aldehyde dehydrogenase: the structure reveals the basis for the retinal specificity of class 1 aldehyde dehydrogenases. Structure. 1998;6(12):1541-51.

Moorman AF, Christoffels VM. Cardiac chamber formation: development, genes, and evolution. Physiol Rev. 2003;83(4):1223-67.

Moss JB, Xavier-Neto J, Shapiro MD, Nayeem SM, McCaffery P, Drager UC, et al. Dynamic patterns of retinoic acid synthesis and response in the developing mammalian heart. Dev Biol. 1998;199(1):55-71.

Nagatomo K, Fujiwara S. Expression of Raldh2, Cyp26 and Hox-1 in normal and retinoic acid-treated Ciona intestinalis embryos. Gene Expr Patterns. 2003;3(3):2737.

Navaratnam V, Kaufman MH, Skepper JN, Barton S, Guttridge KM. Differentiation of the myocardial rudiment of mouse embryos: an ultrastructural study including freezefracture replication. J Anat. 1986;146(65-85.

Niederreither K, Abu-Abed S, Schuhbaur B, Petkovich M, Chambon P, Dolle P. Genetic evidence that oxidative derivatives of retinoic acid are not involved in retinoid signaling during mouse development. Nat Genet. 2002;31(1):84-8.

Niederreither K, McCaffery P, Drager UC, Chambon P, Dolle P. Restricted expression and retinoic acid-induced downregulation of the retinaldehyde dehydrogenase type 2 (RALDH-2) gene during mouse development. Mech Dev. 1997;62(1):67-78.

Niederreither K, Subbarayan V, Dolle P, Chambon P. Embryonic retinoic acid synthesis is essential for early mouse post-implantation development. Nat Genet. 1999;21(4):444-8. 
Nieuwkoop PD, Faber J. Normal table of Xenopus laevis (Daudin) : a systematical and chronological survey of the development from the fertilized egg till the end of metamorphosis. New York: Garland Publishing, Inc; 1994.

Northcutt RG, Gans C. The genesis of neural crest and epidermal placodes: a reinterpretation of vertebrate origins. Q Rev Biol. 1983;58(1):1-28.

Novak J, Benisek M, Hilscherova K. Disruption of retinoid transport, metabolism and signaling by environmental pollutants. Environ Int. 2008;34(6):898-913.

Nubler-Jung K, Arendt D. Enteropneusts and chordate evolution. Curr Biol. 1996;6(4):352-3.

Nüsslein-Volhard C, Dahm R. Zebrafish: a practical approach. New York: Oxford University Press; 2002.

Osmond MK, Butler AJ, Voon FC, Bellairs R. The effects of retinoic acid on heart formation in the early chick embryo. Development. 1991;113(4):1405-17.

Osorio J, Retaux S. The lamprey in evolutionary studies. Dev Genes Evol. 2008;218(5):221-35.

Patwardhan V, Fernandez S, Montgomery M, Litvin J. The rostro-caudal position of cardiac myocytes affect their fate. Dev Dyn. 2000;218(1):123-35.

Percy LR, Potter IC. Aspects of the development and functional morphology of the pericardia heart and associated blood vessels of lampreys. $J$ of Zool. $1991 ; 223(1): 49-66$.

Perez-Pomares JM, Phelps A, Sedmerova M, Carmona R, Gonzalez-Iriarte M, Munoz-Chapuli R, et al. Experimental studies on the spatiotemporal expression of WT1 and RALDH2 in the embryonic avian heart: a model for the regulation of myocardial and valvuloseptal development by epicardially derived cells (EPDCs). Dev Biol. 2002;247(2):307-26.

Pino-Lagos K, Benson MJ, Noelle RJ. Retinoic acid in the immune system. Ann N Y Acad Sci. 2008;1143(170-87.

Plageman TF, Jr., Yutzey KE. Differential expression and function of Tbx5 and Tbx20 in cardiac development. J Biol Chem. 2004;279(18):19026-34.

Plageman TF, Jr., Yutzey KE. T-box genes and heart development: putting the "T" in heart. Dev Dyn. 2005;232(1):11-20.

Pough FH, Janis CM, Heiser JB. Vertebrate life. 6th ed. Upper Saddle River, N.J.: Prentice Hall; 2002.

Rahr H. Circulatory-System of Amphioxus (Branchiostoma-Lanceolatum (Pallas) Light-Microscopic Investigation Based on Intra-Vascular Injection Technique. Acta Zool-Stockholm. 1979;60(1):1-18. 
Rahr $\mathrm{H}$. The Ultrastructure of the Blood-Vessels of Branchiostoma-Lanceolatum (Pallas) (Cephalochordata) .1. Relations between Blood-Vessels, Epithelia, Basal Laminae, and Connective-Tissue. Zoomorphology. 1981;97(1-2):53-74.

Randall DJ. Functional Morphology of Heart in Fishes. Am Zool. 1968;8(2):179-85.

Randall DJ, Davie PS. The hearts of urochordates and cephalochordates. In: Bourne $\mathrm{GH}$, editor. Hearts and Heart-Like Organs. New Yotk: Academic Press; 1980. p. 4160.

Redkar A, Montgomery M, Litvin J. Fate map of early avian cardiac progenitor cells. Development. 2001;128(12):2269-79.

Reijntjes S, Gale E, Maden M. Expression of the retinoic acid catabolising enzyme CYP26B1 in the chick embryo and its regulation by retinoic acid. Gene Expr Patterns. 2003;3(5):621-7.

Reiter JF, Alexander J, Rodaway A, Yelon D, Patient R, Holder N, et al. Gata5 is required for the development of the heart and endoderm in zebrafish. Genes Dev. 1999;13(22):2983-95.

Romer AS. The vertebrate body. 3d ed. Philadelphia,: Saunders; 1962.

Rosenthal N, Xavier-Neto J. From the bottom of the heart: anteroposterior decisions in cardiac muscle differentiation. Curr Opin Cell Biol. 2000;12(6):742-6.

Rossant J, Zirngibl R, Cado D, Shago M, Giguere V. Expression of a retinoic acid response element-hsplacZ transgene defines specific domains of transcriptional activity during mouse embryogenesis. Genes Dev. 1991;5(8):1333-44.

Sakai $Y$, Meno C, Fujii H, Nishino J, Shiratori H, Saijoh $Y$, et al. The retinoic acidinactivating enzyme CYP26 is essential for establishing an uneven distribution of retinoic acid along the anterio-posterior axis within the mouse embryo. Genes Dev. 2001;15(2):213-25.

Satoh N. Developmental Biology of Ascidians. Cambridge: Cambridge University Press 1994.

Sauka-Spengler T, Meulemans D, Jones M, Bronner-Fraser M. Ancient evolutionary origin of the neural crest gene regulatory network. Dev Cell. 2007;13(3):405-20.

Schubert M, Escriva H, Xavier-Neto J, Laudet V. Amphioxus and tunicates as evolutionary model systems. Trends Ecol Evol. 2006;21(5):269-77.

Schubert M, Yu JK, Holland ND, Escriva H, Laudet V, Holland LZ. Retinoic acid signaling acts via Hox1 to establish the posterior limit of the pharynx in the chordate amphioxus. Development. 2005;132(1):61-73. 
Schultheiss TM, Burch JB, Lassar AB. A role for bone morphogenetic proteins in the induction of cardiac myogenesis. Genes Dev. 1997;11(4):451-62.

Schultheiss TM, Xydas S, Lassar AB. Induction of avian cardiac myogenesis by anterior endoderm. Development. 1995;121(12):4203-14.

Simoes-Costa MS, Azambuja AP, Xavier-Neto J. The search for non-chordate retinoic acid signaling: lessons from chordates. J Exp Zoolog B Mol Dev Evol. 2008;310(1):54-72.

Simoes-Costa MS, Vasconcelos M, Sampaio AC, Cravo RM, Linhares VL, Hochgreb T, et al. The evolutionary origin of cardiac chambers. Dev Biol. 2005;277(1):1-15.

Sirbu IO, Gresh L, Barra J, Duester G. Shifting boundaries of retinoic acid activity control hindbrain segmental gene expression. Development. 2005;132(11):2611-22.

Sive HL, Grainger RM, Harland RM. Early Development of Xenopus laevis: A Laboratory Manual. 1 ed. Cold Spring Harbor: Cold Spring Harbor Laboratory Press; 2000.

Stainier DY. Zebrafish genetics and vertebrate heart formation. Nat Rev Genet. 2001;2(1):39-48.

Stainier DY, Fishman MC. Patterning the zebrafish heart tube: acquisition of anteroposterior polarity. Dev Biol. 1992;153(1):91-101.

Stainier DY, Lee RK, Fishman MC. Cardiovascular development in the zebrafish. I. Myocardial fate map and heart tube formation. Development. 1993;119(1):31-40.

Stern CD. The chick embryo--past, present and future as a model system in developmental biology. Mech Dev. 2004;121(9):1011-3.

Stoller JZ, Epstein JA. Cardiac neural crest. Semin Cell Dev Biol. 2005;16(6):704-15.

Stuckmann I, Evans S, Lassar AB. Erythropoietin and retinoic acid, secreted from the epicardium, are required for cardiac myocyte proliferation. Dev Biol. 2003;255(2):334-49.

Swindell EC, Thaller C, Sockanathan S, Petkovich M, Jessell TM, Eichele G. Complementary domains of retinoic acid production and degradation in the early chick embryo. Dev Biol. 1999;216(1):282-96.

Tanaka M, Chen Z, Bartunkova S, Yamasaki N, Izumo S. The cardiac homeobox gene Csx/Nkx2.5 lies genetically upstream of multiple genes essential for heart development. Development. 1999;126(6):1269-80.

Tickle C, Alberts B, Wolpert L, Lee J. Local application of retinoic acid to the limb bond mimics the action of the polarizing region. Nature. 1982;296(5857):564-6. 
Tzahor E, Lassar AB. Wnt signals from the neural tube block ectopic cardiogenesis. Genes Dev. 2001;15(3):255-60.

Volff JN. Genome evolution and biodiversity in teleost fish. Heredity. 2005;94(3):28094.

von Lintig J, Vogt K. Vitamin A formation in animals: molecular identification and functional characterization of carotene cleaving enzymes. J Nutr. 2004;134(1):251S$6 S$.

Waldo KL, Kumiski DH, Wallis KT, Stadt HA, Hutson MR, Platt DH, et al. Conotruncal myocardium arises from a secondary heart field. Development. 2001;128(16):3179-88.

Wang XD, Russell RM, Liu C, Stickel F, Smith DE, Krinsky NI. Beta-oxidation in rabbit liver in vitro and in the perfused ferret liver contributes to retinoic acid biosynthesis from beta-apocarotenoic acids. J Biol Chem. 1996;271(43):26490-8.

Warkman AS, Krieg PA. Xenopus as a model system for vertebrate heart development. Semin Cell Dev Biol. 2007;18(1):46-53.

Watt AJ, Battle MA, Li J, Duncan SA. GATA4 is essential for formation of the proepicardium and regulates cardiogenesis. Proc Natl Acad Sci $U S A$. 2004;101(34):12573-8.

Wessels A, Perez-Pomares JM. The epicardium and epicardially derived cells (EPDCs) as cardiac stem cells. Anat Rec A Discov Mol Cell Evol Biol. 2004;276(1):43-57.

Wilkinson DG. RNA detection using non-radioactive in situ hybridization. Curr Opin Biotechnol. 1995;6(1):20-3.

Wright GM, Keeley FW, Youson JH, Babineau DL. Cartilage in the Atlantic hagfish, Myxine glutinosa. Am J Anat. 1984;169(4):407-24.

Xavier-Neto J, Castro RA, Sampaio AC, Azambuja AP, Castillo HA, Cravo RM, et al. Parallel avenues in the evolution of hearts and pumping organs. Cell Mol Life Sci. 2007;64(6):719-34.

Xavier-Neto J, Neville CM, Shapiro MD, Houghton L, Wang GF, Nikovits W, Jr., et al. A retinoic acid-inducible transgenic marker of sino-atrial development in the mouse heart. Development. 1999;126(12):2677-87.

Xavier-Neto J, Rosenthal N, Silva FA, Matos TG, Hochgreb T, Linhares VL. Retinoid signaling and cardiac anteroposterior segmentation. Genesis. 2001;31(3):97-104.

Xavier-Neto J, Shapiro MD, Houghton L, Rosenthal N. Sequential programs of retinoic acid synthesis in the myocardial and epicardial layers of the developing avian heart. Dev Biol. 2000;219(1):129-41. 
Yamada M, Revelli JP, Eichele G, Barron M, Schwartz RJ. Expression of chick Tbx2, Tbx-3, and Tbx-5 genes during early heart development: evidence for BMP2 induction of Tbx2. Dev Biol. 2000;228(1):95-105.

Yamagishi T, Nakajima Y, Nishimatsu S, Nohno T, Ando K, Nakamura H. Expression of tbx20 RNA during chick heart development. Dev Dyn. 2004;230(3):576-80.

Yelon D. Cardiac patterning and morphogenesis in zebrafish. Dev Dyn. 2001;222(4):552-63.

Yelon D, Horne SA, Stainier DY. Restricted expression of cardiac myosin genes reveals regulated aspects of heart tube assembly in zebrafish. Dev Biol. 1999;214(1):23-37.

Yelon D, Stainier DY. Pattern formation: swimming in retinoic acid. Curr Biol. 2002;12(20):R707-9.

Yu JK, Satou Y, Holland ND, Shin IT, Kohara Y, Satoh N, et al. Axial patterning in cephalochordates and the evolution of the organizer. Nature. 2007;445(7128):613-7.

Yutzey KE, Bader D. Diversification of cardiomyogenic cell lineages during early heart development. Circ Res. 1995;77(2):216-9.

Yutzey KE, Rhee JT, Bader D. Expression of the atrial-specific myosin heavy chain $\mathrm{AMHC} 1$ and the establishment of anteroposterior polarity in the developing chicken heart. Development. 1994;120(4):871-83.

Zhao D, McCaffery P, Ivins KJ, Neve RL, Hogan P, Chin WW, et al. Molecular identification of a major retinoic-acid-synthesizing enzyme, a retinaldehyde-specific dehydrogenase. Eur J Biochem. 1996;240(1):15-22. 